$\mathcal{G S}_{\text {http://dx.doi.org/10.3765/sp.7.3 }}^{\text {Semantics \& Pragmatics Volume 7, Article 3: 1-43, } 2014}$

\title{
Bound 'de re' pronouns and the LFs of attitude reports*
}

\author{
Simon Charlow \\ $N Y U$
}

\author{
Yael Sharvit \\ UCLA
}

Submitted 2011-12-15 / Decision 2012-02-17 / Revision 2012-04-30 / Decision 2012o6-04 / Revision 2012-08-14 / Accepted 2012-09-23 / Published 2014-03-04

\begin{abstract}
An empirical argument is given in support of Percus \& Sauerland's (2003) theory of 'de re' ascription, according to which the internal argument of believe is a function from concept-generators to propositions. The argument concerns pronouns in the scope of attitude verbs that are interpreted both 'de re' and as bound variables. It is argued that more traditional theories of 'de re' ascription - specifically, theories that take the 'res' to be an internal argument of believe - fail to account for such pronouns, as they predict that a pronoun cannot simultaneously be an argument of believe and bound by a quantifier in the scope of believe.
\end{abstract}

Keywords: concept-generators, 'de re' attitudes, pronoun binding, quantifier scope, 'res' movement.

\section{The main claim}

This paper is concerned with attitude reports in which the clausal complement of the attitude verb contains a quantifier and a pronoun bound by

* We want to thank Barbara Abbott, Byron Ahn, Pranav Anand, Gideon Avrahami, Chris Barker, Daniel Büring, Heather Burnett, Nate Charlow, Gennaro Chierchia, Sam Cumming, Amy Rose Deal, Nicholas Fleisher, Michael Glanzberg, Gabriel Greenberg, Irene Heim, Magdalena Kaufmann, Ezra Keshet, Hadas Kotek, Angelika Kratzer, Tim Leffel, Lisa Levinson, Salvador Mascarenhas, Dilip Ninan, Hazel Pearson, Orin Percus, Jessica Rett, Craige Roberts, Paolo Santorio, Philippe Schlenker, Anders Schoubye, Greg Scontras, Mike Solomon, Eric Swanson, Anna Szabolcsi, Rich Thomason, Leah Velleman, Seth Yalcin, Igor Yanovich, two anonymous $S \& P$ reviewers, and audiences at NELS 41, DGfS 2011, the University of Michigan Workshop in Philosophy and Linguistics, the UCLA Philosophy of Language Workshop, and the NYU Semantics Group. The (alphabetically) first author was supported by a Graduate Research Fellowship from the National Science Foundation and NSF grant BCS-o902671.

(C)2014 Simon Charlow \& Yael Sharvit

This is an open-access article distributed under the terms of a Creative Commons Attribution License (http://creativecommons.org/licenses/by/3.o/). 
the quantifier. An example is given in (1), where every female student is the embedded subject and binds a pronoun - her.

(1) John believes that every female student ${ }_{i}$ likes her $_{i}$ mother.

We make two claims regarding (1). Firstly, when (1) is judged against a multiple-guise scenario, it has a reading according to which John roughly thinks the following: " $a$ likes $b$ 's mother, $c$ likes $d$ 's mother and $e$ likes $f$ 's mother". An example of a multiple-guise scenario is one where John comes into contact with every actual female student more than once, and each actual female student appears each time in a different guise, but in John's mind the mapping between women and guises is one-to-one. In other words, if the same woman appears in two different guises, John fails to recognize this and thinks he came into contact with two different women.

Our second claim is that in order to capture all the relevant readings of (1) an in situ theory of 'de re' ascription, such as the one proposed in Percus \& Sauerland (2003), is needed. This theory yields (3) as one possible LF of (1) (in addition to other LFs, such as the 'de dicto' LF in (2)).

(2) John believes- $w_{0}$

$$
\left[\lambda_{1} \text { [every female student- } w_{1}\right.
$$
$\left[\lambda_{2}\left[t_{2}\right.\right.$ likes- $w_{1}$ her 2 mother- $\left.\left.\left.\left.w_{1}\right]\right]\right]\right]$

(3) John believes- $w_{0}$

$$
\begin{aligned}
& \text { [ } \lambda_{8} \lambda_{9} \lambda_{1} \text { [every female student- } w_{0} \\
& \left.\left.\quad\left[\lambda_{2}\left[\left[G_{8} t_{2}\right]-w_{1} \text { likes- } w_{1}\left[G_{9} \text { her } 2\right]-w_{1} \text { mother- } w_{1}\right]\right]\right]\right]
\end{aligned}
$$

We spell out our assumptions about the syntax-semantics interface in $\$ 2$ (e.g. the assumptions regarding traces and world-denoting pronouns). For now, it suffices to note that in (3), the trace of every female student and the pronoun co-indexed with it are embedded inside a complex noun phrase whose head is a pronominal element $-G_{n}$ - which denotes a concept-generator, i.e. a function from individuals to individual concepts. In other words, a concept-generator supplies a guise. Since $G_{8}$ and $G_{9}$ in (3) may potentially supply different guises for the co-indexed (and co-valued) $t_{2}$ and $h e r_{2}$, the resulting reading is such that, "in John's mind", the liker and the likee's daughter are not necessarily the same (though "in the speaker's mind" they are). The semantics assumed for believe, where the clausal complement is the only internal argument, yields the following interpretation: "There is a pair of guises $\left\langle G_{1}, G_{2}\right\rangle$ such that for every actual woman $x$, John believes that $x$-under- $G_{1}$ likes the mother of $x$-under- $G_{2}$ ". We refer to her 2 in (3), which 
Bound 'de re' pronouns and the LFs of attitude reports

is a bound variable but "understood" by John as not co-valued with $t_{2}$, as a 'bound de re' pronoun.

In §2 we motivate the existence of 'bound de re' pronouns on empirical grounds and explain in detail why standard theories cannot account for such pronouns. In $\$ 3$ we present a version of the 'de re' theory of Percus \& Sauerland (2003) that predicts the existence of 'bound de re' pronouns. In $\S 4$ we show that intuitions regarding attitude reports with downwardentailing quantifiers in the clausal complement of the attitude verb (such as John believes that only Mary is French), judged against multiple-guise scenarios, suggest that believe is at least sometimes a universal - rather than existential - quantifier over guises.

\section{What are 'bound de re' pronouns?}

\subsection{The problem and a first attempt at solving it}

Our point of departure is (1), repeated below.

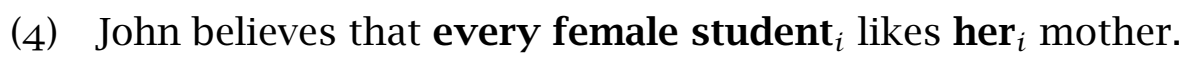

We ask readers to ignore any reading where female student is interpreted 'de dicto' (i.e., any reading that implies that John's thought is roughly of the form: "Every female student likes...") and any reading where her is interpreted referentially (i.e., any reading that implies that John's thought is roughly of the form: “... likes this woman”). Ignoring those 'de dicto' and referential readings, (1) is felicitous in two types of scenarios, corresponding to two different readings - the 'simple bound' reading and the 'bound de re' reading. The 'simple bound' reading is illustrated by a scenario where John is looking at the set of actual female students, saying to himself something like the following (without necessarily acknowledging that the individuals in question are students, or even female): "for each $x$ such that $x$ is one of these individuals here, $x$ likes $x$ 's mother".

However, (1) is felicitous in other, stranger, scenarios. Imagine the set of actual female students is $\{$ Mary, Sally, Betty\} and that John is looking at pairs of pictures of them (i.e., two pictures of Mary, two pictures of Sally, and two pictures of Betty). Again, he may not be aware that Mary, Sally, or Betty are students, or even female. For each pair, he mistakenly thinks its members are distinct from each other. That is to say, pointing first at the first member of the pair 〈Mary, Mary > and then at its second member, he says to himself something along the following lines: "This person likes that person's mother 
[this person $\neq$ that person]"; pointing at the first member of the pair 〈Sally, Sally $>$ and then at its second, he says to himself the same thing: "This person likes that person's mother [this person $\neq$ that person]"; likewise for Betty. We call this reading (first observed in Sharvit 2011) 'bound de re'. ${ }^{1}$

The bound 'de re' reading is not accounted for by most standard theories of attitude reports. Before we show this, let us first elaborate briefly on a data point brought to our attention by Ezra Keshet. The 'bound de re' reading, as we have described it, implies that the predicate mother is interpreted 'de dicto'. For Keshet and two of our consultants, the interpretation of the pronoun her in her mother as a 'de re' pronoun biases mother towards a 'de re' interpretation. This observation does not alter our claim. Examples likes (5a) and (5b), where the 'de re' pronoun isn't embedded inside a DP, as well as examples like (5c), where the 'de re' pronoun is embedded inside a 'de dicto' DP, all have 'bound de re' readings.

(5) a. John believes that every female student ${ }_{i}$ thinks that she ${ }_{i}$ is smart.

b. John believes that every female student ${ }_{i}$ likes herself . $_{i}$.

c. John believes that every female student ${ }_{i}$ likes her $_{i}$ unicorn.

This means that the existence of the 'bound de re' reading is independent of whether the embedding noun phrase - if there is one - is interpreted 'de re' or 'de dicto', and of whether the pronoun is embedded in another noun phrase at all. For this reason, and because most speakers still accept the reading of (1) where mother is interpreted 'de dicto', unless otherwise noted we use the term 'bound de re' reading to refer to the reading where her in her mother is interpreted 'de re' and mother is interpreted 'de dicto'.

To see that standard theories of attitude reports struggle with 'bound de re' readings, it is necessary to take a little excursion into the syntax and semantics of 'de re' ascription. We look at Russellian theories as well as "relational" theories, starting with the former.

First, let us lay out our assumptions about the syntax-semantics interface. (Nothing important hinges on these; our arguments are compatible with a wide range of assumptions about syntax and interpretation.) Following Heim \& Kratzer (1998), we assume the rules of functional application and

1 Though, unsurprisingly, the 'simple de re' reading is more salient, we have yet to find an informant who rejects (1) in this sort of scenario while accepting standard Quine (1956) cases (see §2.2.1). 
Bound 'de re' pronouns and the LFs of attitude reports

predicate modification (as shown in (6a) and (6b), where $\llbracket \cdot \rrbracket^{g}$ is an assigmentparametrized function from pieces of syntax to their interpretations).

(6) a. Functional application: For any branching node $\alpha$ with daughters $\beta, \gamma$ and any assignment $g$, if $\llbracket \beta \rrbracket^{g}\left(\llbracket \gamma \rrbracket^{g}\right)$ is defined, $\llbracket \alpha \rrbracket^{g}=$ $\llbracket \beta \rrbracket^{g}\left(\llbracket \gamma \rrbracket^{g}\right)$.

b. Predicate modification: For any branching node $\alpha$ with daughters $\beta, \gamma$ and any assignment $g$, if $\llbracket \beta \rrbracket^{g}$ and $\llbracket \gamma \rrbracket^{g}$ are type $\langle e, t\rangle, \llbracket \alpha \rrbracket^{g}=$ $\left(\lambda x . \llbracket \beta \rrbracket^{g}(x)=\llbracket \gamma \rrbracket^{g}(x)=1\right)$.

We also assume that quantificational DPs (type $\langle e t, t\rangle$ ) in the object position of transitive verbs aren't interpretable in situ. (This follows from our assumptions about the typing of quantificational DPs and transitive verbs, and the operations available for interpreting branching nodes.) To yield an interpretable structure, quantificational DPs undergo LF movement (i.e. Quantifier Raising or $\mathrm{QR}$ ) to a position of sentential scope. QR leaves behind a trace $t_{n}$ and inserts an operator $\lambda_{n}$ below the movement target such that $\lambda_{n}$ c-commands the co-indexed trace $t_{n}$. For example, the LF of John saw every man is as in (7).

(7) [every man] $\left[\lambda_{1}\right.$ [John saw $\left.\left.t_{1}\right]\right]$

Phrases headed by $\lambda$-operators are interpreted as in (8), yielding (9), of type $\langle e, t\rangle$, which is the proper type to combine with the quantificational DP, and yielding the truth conditions in (10).

(8) Abstraction: For any node $\alpha$,

$$
\llbracket \lambda_{n} \alpha \rrbracket^{g}=\lambda y \cdot \llbracket \alpha \rrbracket^{g[n \rightarrow y]},
$$

where $g[n \rightarrow y]$ is the assignment $g^{\prime}$ differing at most from $g$ in that $g^{\prime}$ maps $n$ to $y$.

(9) $\llbracket \lambda_{1}\left[\text { John saw } t_{1}\right]^{g}=\lambda y$. John saw $y$

(10) $\llbracket(7) \rrbracket^{g}=\llbracket$ every man $\rrbracket^{g}\left(\llbracket \lambda_{1}\left[\right.\right.$ John saw $\left.t_{1} \rrbracket^{g}\right)=1$

iff $\llbracket$ every $\operatorname{man} \rrbracket^{g}(\lambda y$. John saw $y)=1$

iff $\{x: x$ is a man $\} \subseteq\{x:$ John saw $x\}$.

Next, our assumptions about intensionality. To simplify matters, we assume that predicates take pronominal world arguments. Like traces and individual-denoting pronouns, world pronouns can be abstracted over. We adopt the convention that all world pronouns free in the matrix (i.e. not bound 
by a co-indexed, c-commanding $\lambda$-operator) denote the world of utterance. ${ }^{2}$ Also for simplicity (and temporarily), we assume that believe has the Hintikkastyle (Hintikka 1962, 1969) semantics in (11), where $\operatorname{Dox}_{x, w}$ is the set of $x$ 's doxastic alternatives in $w$ - the set of worlds compatible with what $x$ believes in $w .^{3}$

(11) For any $x$ in $D_{e}$, any $w$ in $D_{s}$, any $p$ in $D_{\langle s, t\rangle}$ and any assignment $g$,

$$
\llbracket \text { believe } \rrbracket^{g}(w)(p)(x)=1 \text { iff } \operatorname{Dox}_{x, w} \subseteq\left\{w^{\prime} \in D_{s}: p\left(w^{\prime}\right)=1\right\} \text {. }
$$

Syntactically, we assume intensional verbs like believe trigger $\lambda$-abstraction over world pronouns (so we may have $\lambda$-operators without QR). Thus, John believes it's raining receives the LF in (12a) and the interpretation in (12b).

(12) a. John believes- $w_{0}\left[\lambda_{3}\right.$ [raining- $\left.\left.w_{3}\right]\right]$

b. $\operatorname{Dox}_{\text {John, } @} \subseteq\left\{w \in D_{s}\right.$ : it's raining in $\left.w\right\}$

We now return to the interpretation of quantificational phrases in the scope of attitude reports, beginning with Russellian approaches (approaches that roughly follow Russell 1905). Notice first that the Russellian theory is not expressly built to handle the kind of 'de re' reading we are concerned with; the question is whether this sort of analysis can be extended to deal with 'bound de re' readings.

On the Russellian approach, the interpretation of a noun phrase in the scope of an attitude verb has to do with the noun phrase and the attitude verb's relative scope. For example, when some female student remains in situ, as in (13), the 'de dicto' reading of John believes that some female student is a fool arises. The 'de re' reading arises as a result of some female student QR-ing above believe, as in (14).

a. John believes- $w_{0}$

$\left[\lambda_{2}\right.$ [some female student- $w_{2}$ $\left[\lambda_{1}\left[t_{1}\right.\right.$ is a fool- $\left.\left.\left.\left.w_{2}\right]\right]\right]\right]$

2 For further constraints on the distribution and interpretation of world pronouns, see e.g. Percus (2000). For criticisms of the world-pronoun approach to transparent readings (discussed below, cf. (15)), see Schwager (2010).

3 This a simplified lexical entry, which doesn't take into account beliefs 'de se' (Lewis 1979). A more adequate entry is (i); a centered world $\left\langle w^{\prime}, x^{\prime}\right\rangle$ is a doxastic alternative for $x$ at $w$ just in case for all $x$ knows in $w, w^{\prime}$ is a world she might be living in and $x^{\prime}$ is who she might be in $w^{\prime}$ :

(i) $\llbracket$ believe $\rrbracket^{g}(w)\left(p_{\langle s,\langle e, t\rangle\rangle}\right)(x)=1$ iff $\operatorname{Dox}_{x, w} \subseteq\left\{\left\langle w^{\prime}, x^{\prime}\right\rangle \in D_{s} \times D_{e}: p\left(w^{\prime}\right)\left(x^{\prime}\right)=1\right\}$. 
Bound 'de re' pronouns and the LFs of attitude reports

b. Dox John,@ $\subseteq\left\{w \in D_{s}:\left\{y \in D_{e}: y\right.\right.$ is a female student in $\left.w\right\} \cap$

$$
\left.\left\{y \in D_{e}: y \text { is a fool in } w\right\} \neq \emptyset\right\}
$$

(For each of John's actual doxastic alternatives $w$, there is a female student in $w$ who's a fool in $w$.)

(14) a. [some female student- $w_{0}$ ]

$\left[\lambda_{1}\right.$ [John believes- $w_{0}$

$\left[\lambda_{2}\left[t_{1}\right.\right.$ is a fool- $\left.\left.\left.\left.w_{2}\right]\right]\right]\right]$

b. $\left\{y \in D_{e}: y\right.$ is a female student in @ $\} \cap$

$$
\left\{y \in D_{e}: \text { Dox }_{\text {John,@ }} \subseteq\left\{w \in D_{s}: y \text { is a fool in } w\right\}\right\} \neq \emptyset
$$

(There is an actual female student $y$ such that, in each of John's actual doxastic alternatives $w, y$ is a fool in $w$.)

Since we are assuming that predicates take overt pronominal world arguments, another LF is predicted - one where some female student remains in situ but its world argument is co-indexed with that of believe.

(15) a. John believes- $w_{0}$

$\left[\lambda_{2}\right.$ [some female student- $w_{0}$

$\left[\lambda_{1}\left[t_{1}\right.\right.$ is a fool- $\left.\left.\left.\left.w_{2}\right]\right]\right]\right]$

b. Dox John, $\subseteq \subseteq\left\{w \in D_{s}:\left\{y \in D_{e}: y\right.\right.$ is a female student in $\left.@\right\} \cap$

$$
\left.\left\{y \in D_{e}: y \text { is a fool in } w\right\} \neq \emptyset\right\}
$$

(For each of John's actual doxastic alternatives $w$, there is an actual female student who's a fool is $w$.)

The reading in (15) is the so-called 'intermediate' reading, first observed in Fodor (1970), according to which John's belief is roughly "One of these individuals - I'm not sure who - is a fool" while he is pointing at the actual female students. With universal quantifiers, however, the 'de re' and intermediate readings are indistinguishable:

(16) John believes that every female student is a fool.

Whenever every female student and believe have the same world argument, it does not matter whether we scope every female student above believe-itself a universal quantifier - or not. Both LFs - the Russellian (17a) and the nonRussellian (17b) - yield truth conditions equivalent to (17c).

(17) a. [every female student- $w_{0}$ ]

$\left[\lambda_{1}\right.$ [John believes- $w_{0}$

$\left[\lambda_{2}\left[t_{1}\right.\right.$ is a fool- $\left.\left.\left.\left.w_{2}\right]\right]\right]\right]$ 
b. John believes- $w_{0}$

$\left[\lambda_{2}\right.$ [every female student- $w_{0}$

$\left[\lambda_{1}\left[t_{1}\right.\right.$ is a fool $\left.\left.\left.\left.-w_{2}\right]\right]\right]\right]$

c. $\operatorname{Dox}_{\text {John, } @ \subseteq} \subseteq w \in D_{s}:\left\{y \in D_{e}: y\right.$ is a female student in @ $\} \subseteq$

$$
\left.\left\{y \in D_{e}: y \text { is a fool in } w\right\}\right\}
$$

(For each of John's actual doxastic alternatives $w$, every actual female student is a fool in $w$.)

With similar assumptions, and with the LFs in (18b) and (18a) for John believes that every female student likes her mother, we get (18c) as its 'de re' truth conditions.

a. [every female student- $w_{0}$ ]

$\left[\lambda_{2}\right.$ [John believes- $w_{0}$

[ $\lambda_{1}\left[t_{2}\right.$ likes- $w_{1}$ her 2 mother- $\left.\left.\left.\left.w_{1}\right]\right]\right]\right]$

b. John believes- $w_{0}$

$\left[\lambda_{1}\right.$ [every female student- $w_{0}$

$\left[\lambda_{2}\left[t_{2}\right.\right.$ likes- $w_{1}$ her ${ }_{2}$ mother- $\left.\left.\left.\left.w_{1}\right]\right]\right]\right]$

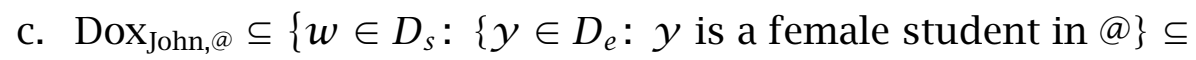

$\left\{y \in D_{e}: y\right.$ likes MOTheR $(w)(y)$ in $\left.\left.w\right\}\right\}$

(For each of John's actual doxastic alternatives $w$, every actual female student $x$ likes in $w$ x's mother in $w$.)

Can we account for 'bound de re' readings with this mechanism? No: (18c) certainly captures the 'simple bound' reading of (1), but crucially not its 'bound de re' reading, according to which "in John's mind" the liker and the likee's daughter are different individuals. Still, it feels like we want to scope the quantifier above believe, the Russellian way, along with the pronoun, as in (19): here $t_{2}$ - corresponding to the liker, and $t_{3}$-corresponding to the likee's daughter are not co-indexed. The problem is, of course, that (19) yields the exact same interpretation as in (18c).

(19) [every female student- $\left.w_{0}\right]$

$\left[\lambda_{2}\left[\right.\right.$ her $_{2}$

$\left[\lambda_{3}\right.$ [John believes- $w_{0}$

$\left[\lambda_{1}\left[t_{2}\right.\right.$ likes- $w_{1} t_{3}$ 's mother- $\left.\left.\left.\left.\left.\left.w_{1}\right]\right]\right]\right]\right]\right]$

The reason we get the exact same truth conditions as in (18c) is that in both (19) and $(18 \mathrm{a}, 18 \mathrm{~b})$ the movement-index $\lambda_{2}$ binds both the trace $t_{2}$ and the 
Bound 'de re' pronouns and the LFs of attitude reports

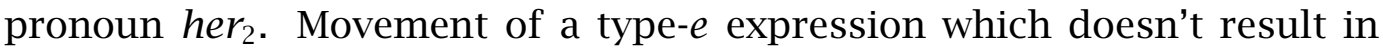
variables becoming unbound is in general semantically vacuous.

\subsection{A second attempt}

\subsection{1 'Res'-movement as an alternative to scoping}

As we will now see, the Russellian approach has problems independent of 'bound de re' cases. Although the Russellian theory of 'de re' ascription we have just entertained does not distinguish between the case where every female student in (1) - on its 'de re' reading - scopes above believe and the case where it doesn't, there are cases where wide-scoping the quantificational phrase gives rise to unattested truth conditions. This happens when the quantifier is downward-entailing. For example, the intuitive truth conditions of (20) on its 'de re' reading are given in (20a); the truth conditions predicted by scoping are given in (2ob). The latter are not attested. (We are using certain instead of believe because the latter is Neg-raising, cf. e.g. Fillmore (1963), Horn (1978).)

(20) John is certain that no female student passed the exam.

a. Actual reading; no female student interpreted in situ: John says to himself, with certainty, pointing at the actual female students: "None of these individuals passed the exam".

b. Non-existent reading; no female student scoped out: No actual female student $x$ is such that John says to himself, with certainty: " $x$ passed the exam".

Notice now that (21), with a downward-entailing quantifier, has a 'bound de re' reading, on which John thinks “this woman doesn't like that woman's mother", for every actual female student.

(21) John is certain that no female student $i$ likes her $_{i}$ mother.

In fact, (21) has a stronger reading than the one just described, which implies that for each pair $\langle x, y\rangle$ in John's mind (i.e., a pair corresponding to a single female), he thinks: “ $x$ doesn't like $y$ 's mother and $y$ doesn't like $x$ 's mother”. We come back to examples such as (21), and their stronger readings, in §4. In the meantime, it suffices to note that (21) has a 'bound de re' reading. Scoping the quantifier above believe would, again, result in incorrect truth conditions, as in (2ob). The conclusion is that 'de re' ascription is not a simple matter of scope, and it is preferable to derive 'de re' readings of quantifiers 
or expressions with quantificational binding of a 'de re' trace or pronoun, without scoping. ${ }^{4}$

In fact, using non-quantificational expressions, Quine (1956) already showed that 'de re' ascription is not a simple matter of scope, arguing instead for a "relational" sense of attitude verbs like believe. Quine made his point by evaluating examples similar to those in (22) against multiple-guise scenarios.

(22) a. Ralph believes that Ortcutt is a spy and, at the same time, he believes that Ortcutt is not a spy.

b. John believes that Mary is French and, at the same time, he believes that Mary is German.

The point is this. While (22a) has a reading that attributes contradictory beliefs to Ralph, it also has a reading that does not: imagine a situation where Ralph sees Ortcutt on two different occasions, but fails to acknowledge that the individual he saw on the first occasion is the same one he saw on the second occasion. (22a) can be true here. But as long as we hang on to the scope theory of 'de re' ascription we won't be able to capture this reading: it does not matter whether we scope Ortcutt above believe or leave it in situ, both options yield the truth conditions in (23c), according to which Ralph is insane: ${ }^{5}$

(23) a. Ralph believes- $w_{0}\left[\lambda_{1}\right.$ [Ortcutt is- $w_{1}$ a spy]] and Ralph believes- $w_{0}\left[\lambda_{1}\right.$ [Ortcutt is- $w_{1}$ not a spy]]

b. [Ortcutt $\left[\lambda_{2}\right.$ [Ralph believes- $w_{0}\left[\lambda_{1}\left[t_{2}\right.\right.$ is- $w_{1}$ a spy]]]]] and [Ortcutt [ $\lambda_{2}$ [Ralph believes- $w_{0}\left[\lambda_{1}\left[t_{2}\right.\right.$ is- $w_{1}$ not a spy]]]]]

c. Dox $X_{\text {Ralph,@ }} \subseteq\left\{w \in D_{s}\right.$ : Ortcutt is a spy and not a spy in $\left.w\right\}$

Likewise, (22b) certainly has a reading according to which John thinks that a single individual, namely Mary, is both French and German. But it also has a reading - the Quine reading - according to which, in John's mind, one woman that he came into contact with is French, and another woman, a different one that he also came into contact with, is German. (The speaker, of

4 To derive the 'de re' reading of John believes that some female student is a fool (represented by (14)) without scoping, at least two strategies have been suggested: the choice-function strategy (Reinhart 1997, Kratzer 1998, 2003), and the singleton-indefinite strategy (Schwarzschild 2002). The choice-function strategy does not treat some female student as a quantifier at all, and the singleton-indefinite strategy treats it as a quantifier with a singleton set restrictor. 5 Nor does simply making names non-rigid designators help matters since multiple-guise scenarios require multiple "Ortcutts" at each of Ralph's belief-alternatives. 
Bound 'de re' pronouns and the LFs of attitude reports

course, knows that these women are one and the same.) Scoping only gives us the former reading.

Quine's point is, of course, applicable to quantifiers as well. For example, John believes that every female student is French and, at the same time, he believes that every female student is German has a reading according to which John sees the same women on different occasions, and regarding every woman, he holds a pair of beliefs just like the pair he holds regarding Mary in (22b). Scoping, as we just saw, would not help us arrive at the relevant reading.

Yet it still feels like the 'bound de re' reading of (1) "needs" a wide-scoping LF à la (19), where the trace and the pronoun are contra-indexed. In §3 we will see that a specific solution to Quine's problem (namely, the solution due to Percus \& Sauerland 2003) also solves the 'bound de re' problem posed by (1), by providing an LF that is not quite like (19), but which nevetheless leads to the reading where the liker and the daughter of the likee are not necessarily the same in John's mind (though they remain identical in the speaker's mind). Before introducing that solution, let us look at some traditional solutions to Quine's problem and convince ourselves that they, too, cannot solve the 'bound de re' pronouns problem posed by (1).

Cresswell \& von Stechow (1982) (following Kaplan 1968 and Lewis 1979) propose that believere ${ }^{\mathrm{re}}$, defined in (24), is the main verb in 'de re' ascriptions such as John believes that Mary is French. ${ }^{6}$ This verb is "relational": it takes the 'res' - the individual about whom John holds his belief (here Mary) - as its first internal argument, and a property-denoting expression of type $\langle e,\langle s, t\rangle\rangle$ as its second internal argument. It requires an acquaintance relation to hold uniquely between the believer and the 'res' in the actual world, and between the believer and some individual in the believer's doxastic alternatives. Since the acquaintance relation only ever relates the attitude holder to a single individual at each relevant world, we'll speak, equivalently, of "acquaintance

6 We are again simplifying (see fn. 3). A more adequate version of believe re $^{\text {is this: }}$

(i) $\llbracket$ believe $^{\mathrm{re}} \rrbracket^{g}(w)(z)\left(P_{\langle e,\langle s,\langle e, t\rangle\rangle\rangle}\right)(x)=1$ iff there is a suitable acquaintance function $F$ such that
a. $F(w)(x)=z$, and
b. $\operatorname{Dox}_{x, w} \subseteq\left\{\left\langle w^{\prime}, x^{\prime}\right\rangle \in D_{s} \times D_{e}: P\left(F\left(w^{\prime}\right)\left(x^{\prime}\right)\right)\left(w^{\prime}\right)\left(x^{\prime}\right)=1\right\}$. 
functions" as defined in (25). Doing so allows us to considerably simplify the metalanguage. ${ }^{7}$

(24) For any $x$ and $z$ in $D_{e}$, any $w$ in $D_{s}$, any $P$ in $D_{\langle e,\langle s, t\rangle\rangle}$ and any assignment $g$,

$$
\text { [believe }{ }^{\mathrm{re}} \rrbracket^{g}(w)(z)(P)(x)=1
$$

iff there's a suitable acquaintance function $F$ such that

i. $F(w)=z$, and

ii. $\operatorname{Dox}_{x, w} \subseteq\left\{w^{\prime} \in D_{s}: P\left(F\left(w^{\prime}\right)\right)\left(w^{\prime}\right)=1\right\}$.

This second condition can be paraphrased thus: "For all doxastic alternatives $w^{\prime}$ of $x$ in $w, F\left(w^{\prime}\right)$ has property $P$ in $w^{\prime} . "$

(25) Acquaintance functions: Given a suitable acquaintance relation $R$, attitude holder $x$, and world $w, F$ is a suitable acquaintance function iff $F(w)$ is the unique $y$ such that $R(w, x, y)$.

For a case like (22b), an acquaintance relation like

$$
\lambda w \lambda y \lambda x . x \text { saw } y \text { wearing a gray coat in } w
$$

might underlie $F$ - which might in turn be something like

$\lambda w$. the $y$ such that John saw $y$ wearing a gray coat in $w$

- thereby supplying what we have been calling a guise. Thus, if the 'res' is Mary, John can ascribe French-ness to her under one acquaintance function, or guise ("the woman John saw wearing a red dress is French"), and Germanness under another acquaintance function, or guise ("the woman John saw wearing a gray coat is German"). The truth conditions of the 'de re' reading of John believes that Mary is French are then as in (26).

(26) There is a suitable acquaintance function $F$ such that

i. $F(@)=$ Mary, and

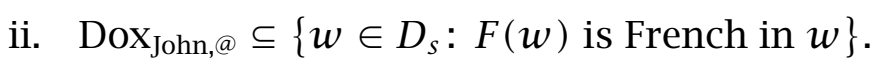

7 Two notes: (i) The definition refers to an acquaintance function's suitability. We intend that an acquaintance function is 'suitable' only if the corresponding acquaintance relation is 'vivid' in the sense of Kaplan (1968). The restriction to vivid acquaintance functions is designed to avoid the so-called 'shortest-spy problem'. Aloni (2005) argues that vividness is actually the wrong notion: the relevant acquaintance functions (relations) should instead be non-trivializing. We are happy to adopt this; near as we can see, it's orthogonal to our arguments. (ii) We are modeling all the interesting entailments here as non-presuppositional. We intend this only as a simplifying assumption. 
Bound 'de re' pronouns and the LFs of attitude reports

To account for the 'de re' truth conditions of John believes that every female student is French, (28), assume that a plurality or set, such as the set of actual female students, can be a 'res'. (We assume, following Schwarzschild (1996), that both singularities and pluralities are sets of individuals, of type e.) Example (27) gives the revised semantics for believe, and (28) gives 'de re' truth conditions for John believes that every female student is French. Note that $F$ in (27) and (28) is a "parametrized" acquaintance function; this effectively means that for every individual in the 'res' a potentially different acquaintance function is introduced. ${ }^{8}$

(27) For any (singular or plural) $y$ in $D_{e}$, any singular $x$ in $D_{e}$, any $w$ in $D_{s}$, any $P$ in $D_{\langle e,\langle s, t\rangle\rangle}$ and any assignment $g$,

$$
\text { 【believe }{ }^{\mathrm{re}} \rrbracket^{g}(w)(y)(P)(x)=1
$$

iff there is a function $F$ from members of $D_{e}$ to suitable acquaintance functions such that

i. for all $z$ in $y, F_{z}(w)=z$, and

ii. $\operatorname{Dox}_{x, w} \subseteq\left\{w^{\prime} \in D_{s}\right.$ :

$$
\left.P\left(\left\{z^{\prime}: \text { there is a } z^{\prime \prime} \text { in } y \text { such that } z^{\prime}=F_{z^{\prime \prime}}\left(w^{\prime}\right)\right\}\right)\left(w^{\prime}\right)=1\right\} .
$$

(28) There is a function $F$ from individuals to suitable acquaintance functions, such that

$$
\begin{aligned}
& \left\{x \in D_{e}: x \text { is a female student in } @\right\} \subseteq \\
& \left\{z \in D_{e}: \quad \text { i. } \quad F_{z}(@)=z\right. \text {, and } \\
& \text { ii. Dox John,@ } \left.\subseteq\left\{w \in D_{s}: F_{z}(w) \text { is French in } w\right\}\right\} \text {. }
\end{aligned}
$$

(For each actual female student $z$, for each of John's actual doxastic alternatives $w, F_{z}(w)$ is French in $w$.)

But what is the LF which these truth conditions are read off? Various answers have been suggested in the literature. For example, the LF in (29) follows Heim's (1994) version of the Kaplan/Lewis/Cresswell \& von Stechow idea, called 'res'-movement: the 'res' is not just a semantic argument of believere, but also a syntactic argument, as it moves out of the clausal complement, leaving behind an abstracted-over trace. $\left(t_{3}\right.$ in (29a) is a trace of type $e$, and $T_{3}$ in (2gb) is a trace of type $\left.\langle e, t\rangle.\right)^{9}$

8 To keep things readable, (28) is given without the redundant lower universal quantifier. 9 Here ' $\langle e, t\rangle$ ' designates the type of sets of atomic individuals. The 'de re' LFs of John believes that some female student is French are (see fn. 4): 
a. John [believere $-w_{0}$ Mary]

$$
\left[\lambda_{3} \lambda_{1}\left[t_{3} \text { is French- } w_{1}\right]\right]
$$

b. John [believere $-w_{0}$ female-student- $w_{0}$ ]

$$
\left.\left.\left[\lambda_{3} \lambda_{1} \text { [[every } T_{3}\right] \text { is French- } w_{1}\right]\right]
$$

Clearly, this theory involves unorthodox movement. One obvious concern is that the moved 'res' does not c-command its trace. Furthermore, in some cases such as (30), where Mary (construed 'de re') is inside a conjoined noun phrase, 'res'-movement violates one of the island constraints that seems the least violable, namely the Coordinate Structure Constraint (cf. Ross 1967).

(30) John mistakenly believes he has a unicorn, and furthermore, he believes that his unicorn and Mary are fools.

Other theories have similar problems, and we will not review them here; we take 'res'-movement to be representative of this type of theories. Importantly, 'bound de re' readings are not captured by 'res'-movement. Let us elaborate on this point.

\subsection{2 'Res'-movement and 'bound de re' pronouns}

Making her an argument of believe as in (31) indeed creates an LF for (1) where the embedded traces are not co-indexed, but it takes her outside the scope of every, with the result that her can only be interpreted referentially. Notice that (31) requires us to say that believe is type-flexible and can take more than one 'res'-argument (something we need to assume anyway, because of examples such as John believes that Mary introduced Bill to Sue). ${ }^{10}$

(i) a. John [believes- $w_{0} f^{\mathrm{CH}}\left(\right.$ female-student- $\left.w_{0}\right)$ ]

$$
\left[\lambda_{3} \lambda_{1}\left[t_{3} \text { is French- } w_{1}\right]\right]
$$

b. John [believes- $w_{0}$ female-student- $w_{0}$ ]

$$
\left[\lambda_{3} \lambda_{1} \text { [some } T_{3}\right.
$$

$\left[\lambda_{2}\left[t_{2}\right.\right.$ is French- $\left.\left.\left.\left.w_{1}\right]\right]\right]\right]$

Since the 'res' argument in (i) is a singular individual, that LF doesn't require John to be acquainted with the entire set of female students.

$10 \llbracket$ believe ${ }^{\mathrm{re}} \rrbracket^{g}(w)\left(z_{1}, z_{2}, \ldots, z_{n}\right)(P)(x)=1$ iff there is a function $F$ from individuals to suitable acquaintance functions such that

i. $F_{z_{1}}(w)=z_{1}, F_{z_{2}}(w)=z_{2}, \ldots, F_{z_{n}}(w)=z_{n}$; and

ii. $\operatorname{Dox}_{x, w} \subseteq\left\{w^{\prime} \in D_{s}: P\left(F_{z_{1}}\left(w^{\prime}\right)\right)\left(F_{z_{2}}\left(w^{\prime}\right)\right) \ldots\left(F_{z_{n}}\left(w^{\prime}\right)\right)\left(w^{\prime}\right)=1\right\}$. 
Bound 'de re' pronouns and the LFs of attitude reports

(31) John [[believe ${ }^{\mathrm{re}}-w_{0}$ her $\left._{3}\right]$ female-student- $w_{0}$ ]

$$
\begin{aligned}
& {\left[\lambda _ { 3 } \lambda _ { 4 } \lambda _ { 1 } \left[\left[\text { every } T_{4}\right]\right.\right.} \\
& \left.\left.\quad\left[\lambda_{2}\left[t_{2} \text { likes- } w_{1} t_{3} \text { 's mother- } w_{1}\right]\right]\right]\right]
\end{aligned}
$$

Moreover, if we 'res'-move female student but leave the pronoun in situ, we run into the same problem that afflicted the Russellian LFs - namely that the pronoun is still bound "in John's mind."

Notice now that we would get the right reading if we scoped every female student all the way up, letting it bind both a trace-'res' and a pronoun-'res', which are co-indexed with each other.

(32) [every female-student- $w_{0}$ ]

$$
\begin{aligned}
& \left.\left[\lambda_{2} \text { [John [[believere }-w_{0} t_{2}\right] \text { her }_{2}\right] \\
& \left.\left.\quad\left[\lambda_{4} \lambda_{3} \lambda_{1}\left[t_{4} \text { likes- } w_{1} t_{3} \text { 's mother- } w_{1}\right]\right]\right]\right]
\end{aligned}
$$

But this option is excluded in view of the problems discussed in connection with (20)-(21) (see §2.2.1).

A more promising attempt might be (33), on the assumption that $\llbracket$ her $\rrbracket^{g}$ is the identity function (i.e. $f: f$ is of type $\langle e, e\rangle$ and for every $x \in \operatorname{Dom}(f)$, $f(x)=x)^{11}$ Then $t_{3}$ is a trace of type $\langle e, e\rangle$. This yields the (simplified) truth conditions in (34). Informally, the idea is that the identity function is replaced in John's doxastic alternatives; very roughly, his confusion about the identity of the identity function "destroys the binding" in his mind. To make this work, we'd have to assume that her occurs with a silent type-e pronominal complement pro $_{n}$; in normal, non-'res'-movement cases, the fact that $\llbracket$ her $\rrbracket^{g}=$ IDENT ensures that $\llbracket$ her pro $_{n} \rrbracket^{g}=\llbracket$ pro $_{n} \rrbracket^{g}$.

(33) John [[believere $-w_{0}$ her] female-student- $\left.w_{0}\right]$

$$
\begin{aligned}
& {\left[\lambda _ { 3 } \lambda _ { 4 } \lambda _ { 1 } \left[\left[\text { every } T_{4}\right]\right.\right.} \\
& \left.\left.\quad\left[\lambda_{2}\left[t_{2} \text { likes- } w_{1}\left[t_{3} \text { pro }{ }_{2}\right] \text { 's mother- } w_{1}\right]\right]\right]\right]
\end{aligned}
$$

(34) There is a suitable acquaintance function $F$ (of type $\langle s,\langle e, e\rangle\rangle$ ) and a suitable parametrized acquaintance function $H$ (of type $\langle e,\langle s, e\rangle\rangle$ ), such that

a. $F(@)=$ IDENT; and

11 See Jacobson (1999) for a proposal (albeit one quite different from the one we're considering here) where pronouns denote identity functions. See Elbourne (2005) for a proposal that treats pronouns as morphologically complex in a rather similar way - i.e. with silent reference-fixing content. 
b. $\left\{y \in D_{e}: y\right.$ is a female student in $\left.@\right\} \subseteq$

$$
\begin{aligned}
& \left\{x \in D_{e}: \quad \text { i. } H_{x}(@)=x\right. \text {, and } \\
& \text { ii. DoX John,@ } \subseteq\left\{w \in D_{s}: H_{x}(w) \text { likes in } w\right. \\
& \left.\left.\operatorname{MOTHER}(w)\left(F(w)\left(H_{x}(w)\right)\right)\right\}\right\} .
\end{aligned}
$$

$F$ is a suitable acquaintance function that picks out an $\langle e, e\rangle$ function for each $w$ in its domain, and $H$ supplies, for every $x$ in its domain, a suitable acquaintance function that picks out an individual at each $w$ in its domain (cf. (28)).

This would require us to say that John is acquainted with the identity function (and we would have to adapt the semantics of believere accordingly). The idea is that John can fail to recognize the identity function and mistake it for some other function, with the result that, in his mind, John is pointing at two different individuals, for every pair of the form $\langle x, x\rangle$ that he is actually pointing at.

Suppose, for instance, that the set of actual female students is $\{a, b, c\}$ and that John is looking at the pairs $\langle a, a\rangle,\langle b, b\rangle,\langle c, c\rangle$ (more accurately, pairs of the corresponding pictures), but he thinks the pairs are $\langle a, b\rangle,\langle b, c\rangle$, $\langle c, a\rangle$ (and he doesn't know that $a, b$, and $c$ are students). In addition, the values for $F$ and $H$ in (34) are as in (35), and (36) gives more information about what goes on "in John's mind".

(35) a. $F=\lambda w$. the $\langle e, e\rangle$-function indirectly presented to John in $w$ via the pairs he's looking at in $w$.

b. $H=\{\langle a, \lambda w$. the $z$ such that John sees $z$ in a red suit in $w\rangle$, $\langle b, \lambda w$. the $z$ such that John sees $z$ in a blue suit in $w\rangle$, $\langle c, \lambda w$. the $z$ such that John sees $z$ in a green suit in $w\rangle\}$

(36) For every $w^{\prime}$ in Dox $\mathrm{J}_{\mathrm{John}, @}$

a. $F\left(w^{\prime}\right)$ agrees with IDENT on every $x$ in its domain, except that

$$
\begin{aligned}
& F\left(w^{\prime}\right)(a)=b, \\
& F\left(w^{\prime}\right)(b)=c, \quad \text { and } \\
& F\left(w^{\prime}\right)(c)=a ;
\end{aligned}
$$

b. For every actual female student $x$, it is not the case that $H_{x}\left(w^{\prime}\right)$ is a student in $w^{\prime}$; and 
Bound 'de re' pronouns and the LFs of attitude reports

C.

$$
\begin{aligned}
& H_{a}\left(w^{\prime}\right)=a, \\
& H_{b}\left(w^{\prime}\right)=b, \text { and } \\
& H_{c}\left(w^{\prime}\right)=c .
\end{aligned}
$$

It then follows from (34) that in every $w^{\prime}$ in Dox John,@ $_{a} a$ likes $b$ 's mother, $b$ likes $c$ 's mother, and $c$ likes $a$ 's mother (instead of believing that $a$ likes $a$ 's mother, $b$ likes $b$ 's mother, and $c$ likes $c$ 's mother - a belief which would be more faithful to the actual pairs he is looking at). This correctly predicts that John believes that every female student likes her mother is felicitous even without binding "in John's mind".

Clearly, any proposal along these lines should motivate the assumption that individuals can be acquainted with functions. Since we'll ultimately reject this idea, we don't attempt to provide this foundation ourselves. Rather, we'll briefly explore the ramifications of this approach, should an independent motivation be adduced.

But here is a problem: if we do assume that acquaintance with functions is as described above, we predict, counter-intuitively, that (1) is felicitous in a situation where John sees every actual female student once, identifies each student correctly and says "for each $x$ such that $x$ is one of these individuals, $x$ likes the mother of $x$ 's aunt". According to the LF in (33), this can happen, for example, when John confuses the identity function with the aunt-of function (even if he doesn't have any confusion regarding the identity of the individuals themselves). If this problem cannot be overcome, the generation of (33) must somehow be blocked, in which case the 'bound de re' reading would remain unaccounted for.

Gennaro Chierchia (p.c.) suggests a way to block this undesired reading, without blocking the generation of (33). Suppose there is a constraint on the kind of acquaintance functions which can possibly figure in 'de re' construals of $\langle e, e\rangle$-functions. Specifically, suppose an individual $y$ can be acquainted in the actual world with a function $f$ (of type $\langle e, e\rangle$ ) through an acquaintance function $F$ only if $F$ is appropriate for $y$ and $f$ in the actual world - that is to say, only if there is a pair $\langle J, K\rangle$ such that for each $x$ in $\operatorname{Dom}(f)$,

i. $J_{x}$ is a suitable acquaintance function which delivers $x$ in the actual world (though it may deliver someone else in $y$ 's doxastic alternatives), and 
ii. $K_{x}$ is a suitable acquaintance function which delivers $f(x)$ in the actual world (though it may deliver someone else in $y$ 's doxastic alternatives).

Furthermore, for any $w \in \operatorname{Dox}_{y, @}$ and any $\left\langle z, z^{\prime}\right\rangle$, it will be the case that $\left\langle z, z^{\prime}\right\rangle$ is in $F(w)$ if and only if there is a $z^{\prime \prime}$ such that

$$
\begin{aligned}
\left\langle z^{\prime \prime}, f\left(z^{\prime \prime}\right)\right\rangle & \left.=\left\langle J_{z^{\prime \prime}} @\right), K_{z^{\prime \prime}}(@)\right\rangle, \quad \text { and } \\
\left\langle z, z^{\prime}\right\rangle & =\left\langle J_{z^{\prime \prime}}(w), K_{z^{\prime \prime}}(w)\right\rangle .
\end{aligned}
$$

Table 1 illustrates such a state of affairs: $f$ is some $\langle e, e\rangle$-function that John's acquainted with in the actual world - say, the function from \{Mary, Sally, Betty\} into \{Mary, Sally, Betty\} such that

$$
\begin{aligned}
& f \text { (Mary) }=\text { Sally } \\
& f(\text { Sally })=\text { Betty }, \quad \text { and } \\
& f(\text { Betty })=\text { Mary. }
\end{aligned}
$$

Also, $w_{1}$ is a doxastic alternative of John's at @; and each cell shows which individuals are picked out by $J_{x}$ and $K_{x}$, for every $x$ in $\operatorname{Dom}(f)$. For example, suppose that

$$
\begin{aligned}
J_{\text {Mary }} & =\lambda w . \iota x . \text { John likes- } w x, \text { and } \\
K_{\text {Mary }} & =\lambda w . \iota x . \text { John hates- } w x .
\end{aligned}
$$

So the presence of $\left\langle J_{\text {Mary }}(@)=\right.$ Mary, $K_{\text {Mary }}(@)=f($ Mary $\left.)\right\rangle$ in the "original function" won't license the presence of any $\langle a, b\rangle$ in the "mistaken function" at $w_{1}$ unless

$$
\begin{aligned}
& a=\iota x . \text { John likes- } w_{1} x, \text { and } \\
& b=\iota x . \text { John hates- } w_{1} x .
\end{aligned}
$$

Likewise, the presence of $\langle$ Betty, $f$ (Mary) $\rangle$ in the "mistaken function" at $w_{1}$ is not licensed (by virtue of $J$ and $K$ ) unless there is a pair $\langle a, b\rangle$ in the "original

$$
\begin{array}{cc}
w_{1} \\
\left\langle J_{\text {Mary }}(@)=\text { Mary, } K_{\text {Mary }}(@)=f(\text { Mary })\right\rangle & \left\langle J_{\text {Mary }}\left(w_{1}\right)=\text { Betty, } K_{\text {Mary }}\left(w_{1}\right)=f(\text { Mary })\right\rangle \\
\left\langle J_{\text {Sally }}(@)=\text { Sally, } K_{\text {Sally }}(@)=f(\text { Sally })\right\rangle & \left\langle J_{\text {Sally }}\left(w_{1}\right)=\text { Sally, } K_{\text {Sally }}\left(w_{1}\right)=f(\text { Sally })\right\rangle \\
\left\langle J_{\text {Betty }}(@)=\text { Betty, } K_{\text {Betty }}(@)=f(\text { Betty })\right\rangle & \left\langle J_{\text {Betty }}\left(w_{1}\right)=\text { Mary, } K_{\text {Betty }}\left(w_{1}\right)=f(\text { Mary })\right\rangle
\end{array}
$$

Table 1 Illustration of "extensional acquaintance" 
Bound 'de re' pronouns and the LFs of attitude reports

function" such that

$$
\begin{aligned}
a & =J_{a}(@), \\
b & =K_{a}(@), \\
\text { Betty } & =J_{a}\left(w_{1}\right), \text { and } \\
f(\text { Mary }) & =K_{a}\left(w_{1}\right) .
\end{aligned}
$$

For convenience, we call this suggested constraint on acquaintance with functions "extensional acquaintance".

Given that the identity function is of type $\langle e, e\rangle$, this constraint holds of it as well, with the result that John cannot simply mistake the identity function for the aunt-of function (this also means that John is acquainted with some sub-function of IDENT). The reason is that the identity function is the set of pairs $\langle x, x\rangle$, and the aunt-of function is a set of pairs $\langle x, y\rangle$ such that, presumably, $x \neq y$. So the only way for John to be confused about IDENT is for John to be confused about (some of) the individuals related to themselves by it. Put simply, if he isn't mistaken about the individuals, he cannot be mistaken about the function. This blocks the undesired reading of (33), where John does not misidentify the individuals themselves, but rather the identity function itself. If this solution is on the right track, we can account for the 'bound de re' reading with (33) without generating unattested readings.

But this conclusion is incorrect. Here is a scenario in which the attitude holder is acquainted with the function but where John thinks every female student likes her mother nevertheless cannot be truthfully uttered. Suppose the set of actual female students is as before. In addition, the set of actual female professors is $\left\{d_{1}, d_{2}, d_{3}\right\}$. John is looking at the following three sets of pictures, each consisting of three pairs: the first three pairs are $\langle a, a\rangle,\langle b, b\rangle,\langle c, c\rangle$, the second three pairs are also $\langle a, a\rangle,\langle b, b\rangle,\langle c, c\rangle$, and the third three pairs are $\left\langle d_{1}, d_{1}\right\rangle,\left\langle d_{2}, d_{2}\right\rangle,\left\langle d_{3}, d_{3}\right\rangle$. Suppose the values for $F$ and $H$ in (34) are as in (37) and (38).

(37) $F=\lambda w$. the $\langle e, e\rangle$ function indirectly presented to John via the $1^{\text {st }}, 2^{\text {nd }}, 3^{r d}, 7^{\text {th }}, 8^{\text {th }}$ and $9^{\text {th }}$ pairs he is looking at in $w$ (e.g. in @ the pairs $\langle a, a\rangle,\langle b, b\rangle,\langle c, c\rangle,\left\langle d_{1}, d_{1}\right\rangle,\left\langle d_{2}, d_{2}\right\rangle,\left\langle d_{3}, d_{3}\right\rangle$ ) 


$$
\begin{aligned}
H=\{ & \langle a, \lambda w . \text { the woman } z \text { s.t. John sees } z \text { in a red suit in } w\rangle, \\
& \langle b, \lambda w . \text { the woman } z \text { s.t. John sees } z \text { in a blue suit in } w\rangle, \\
& \langle c, \lambda w . \text { the woman } z \text { s.t. John sees } z \text { in a green suit in } w\rangle, \\
& \left\langle d_{1}, \lambda w . \text { the woman } z \text { s.t. John sees } z \text { in a yellow suit in } w\right\rangle, \\
& \left\langle d_{2}, \lambda w . \text { the woman } z \text { s.t. John sees } z \text { in a purple suit in } w\right\rangle, \\
& \left.\left\langle d_{3}, \lambda w . \text { the woman } z \text { s.t. John sees } z \text { in a pink suit in } w\right\rangle\right\}
\end{aligned}
$$

Suppose John thinks: (i) the first three pairs are $\left\langle d_{1}, d_{1}\right\rangle,\left\langle d_{2}, d_{2}\right\rangle,\left\langle d_{3}, d_{3}\right\rangle$, the second three pairs are $\langle a, a\rangle,\langle b, b\rangle,\langle c, c\rangle$, and the third three pairs are $\left\langle a, d_{1}\right\rangle,\left\langle b, d_{2}\right\rangle,\left\langle c, d_{3}\right\rangle$; and (ii) for each pair in the first and second threesomes of pairs, the first member hates the second member's mother, and for each pair in the third threesome of pairs, the first member likes the second member's mother. (39) gives more information about what goes on in the actual world and "in John's mind".

a. $F(@)=\left\{\langle a, a\rangle,\langle b, b\rangle,\langle c, c\rangle,\left\langle d_{1}, d_{1}\right\rangle,\left\langle d_{2}, d_{2}\right\rangle,\left\langle d_{3}, d_{3}\right\rangle\right\}$;

b. For every $w^{\prime}$ in Dox John,@,

i. $\quad F\left(w^{\prime}\right)(a)=d_{1}, \quad F\left(w^{\prime}\right)(b)=d_{2}, \quad F\left(w^{\prime}\right)(c)=d_{3}$, $F\left(w^{\prime}\right)\left(d_{1}\right)=d_{1}, \quad F\left(w^{\prime}\right)\left(d_{2}\right)=d_{2}, \quad F\left(w^{\prime}\right)\left(d_{3}\right)=d_{3} ;$

ii. For every $x$ such that $x$ is a female student in @, $H_{x}\left(w^{\prime}\right)$ is not a female student in $w^{\prime}$; and

iii. $H_{a}\left(w^{\prime}\right)=a, \quad H_{b}\left(w^{\prime}\right)=b, \quad H_{c}\left(w^{\prime}\right)=c$.

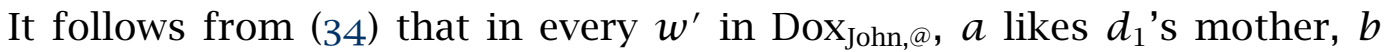
likes $d_{2}$ 's mother, and $c$ likes $d_{3}$ 's mother. Importantly, the "mistaken function" - $\left\{\left\langle d_{1}, d_{1}\right\rangle,\left\langle d_{2}, d_{2}\right\rangle,\left\langle d_{3}, d_{3}\right\rangle,\left\langle a, d_{1}\right\rangle,\left\langle b, d_{2}\right\rangle,\left\langle c, d_{3}\right\rangle\right\}$ - obeys "extensional acquaintance" since each "mistaken" pair corresponds to a pair in IDENT. For instance, $\left\langle a, d_{1}\right\rangle$ is in the mistaken function since, looking at $\left\langle d_{1}, d_{1}\right\rangle$ (which is in IDENT), John thinks he is looking at $\left\langle a, d_{1}\right\rangle$. Similarly for the remaining pairs. ${ }^{12}$

12 Here are possible values for $F(@)$ and $F(w)$, for any $w \in \operatorname{Dox}_{\text {John,@ }}$ (notice that John can be acquainted with each individual by more than one acquaintance relation):

(i) IDENT (=F(@)):

$\left\{\left\langle\right.\right.$ "the $1^{\text {st }} y$ to John's left in @” $(=a)$, "the $1^{\text {st }} y$ to John's right in @” $\left.(=a)\right\rangle$, 〈"the $2^{\text {nd }} y$ to John's left in @” $(=b)$, "the $2^{\text {nd }} y$ to John's right in @” $(=b)$, $\left\langle\right.$ "the $3^{r d} y$ to John's left in @” $(=c)$, "the $3^{r d} y$ to John's right in @” $\left.(=c)\right\rangle$, 〈"the $7^{\text {th }} y$ to John's left in @" $\left(=d_{1}\right)$, "the $7^{\text {th }} y$ to John's right in @" $\left(=d_{1}\right)$ ), 〈"the $8^{\text {th }} y$ to John's left in @” $\left(=d_{2}\right)$, “the $8^{\text {th }} y$ to John's right in @” $\left(=d_{2}\right)$ ), 〈"the $9^{\text {th }} y$ to John's left in @” $\left(=d_{3}\right)$, “the $9^{\text {th }} y$ to John's right in @” $\left(=d_{3}\right)$ ) 
Bound 'de re' pronouns and the LFs of attitude reports

So once again, $F$ picks out IDENT in @, and we predict John believes that every female student likes her mother to be felicitous. But this prediction is wrong; the sentence cannot report the state of affairs just described. In a sense, the confusion required by extensional acquaintance has happened "at the wrong place" - since only the female students matter for the "bound de re' reading, the sub-function of IDENT which we, the theorists, want to inform extensional acquaintance is $\{\langle a, a\rangle,\langle b, b\rangle,\langle c, c\rangle\}$; but instead, extensional acquaintance lets pass the "mistaken sub-function" $\left\{\left\langle a, d_{1}\right\rangle,\left\langle b, d_{2}\right\rangle,\left\langle c, d_{3}\right\rangle\right\}$ in virtue of a different sub-function of IDENT - namely, $\left\{\left\langle d_{1}, d_{1}\right\rangle,\left\langle d_{2}, d_{2}\right\rangle\right.$, $\left.\left\langle d_{3}, d_{3}\right\rangle\right\}$. Absent an ad hoc appeal to context, it is not clear how this worry can be remedied; doing so clearly requires tools beyond the notion of extensional acquaintance (especially in view of the fact that John believes every female student likes her mother can be uttered felicitously in a similar scenario, where John makes the same identification mistakes, but also thinks that every first member in the second threesome likes the mother of the corresponding second member, and every first member in the third threesome hates the mother of the corresponding second member).

We conclude that (33) should not be generated. The reason for this, we've argued, is not that acquaintance with functions is constrained by "extensional acquaintance”. Rather, (33) must violate some grammatical constraint. We do not commit ourselves to what that constraint is, though the following possibility comes to mind: suppose pronouns are always of type $e$, even when they are complex (i.e., composed of a function element of type $\langle e, e\rangle$ and an argument element of type $e$, as is the case in (33)), and can be interpreted 'de re' only as a single unit of type $e$. Such a constraint blocks the generation of (33), but still generates (31), which does not yield the 'bound de re' reading (as we saw). ${ }^{13}$

(ii) $\quad F(w)$, for every $w \in \operatorname{Dox}_{\text {John, } @ \text {, }}$

\{〈"the $1^{\text {st }} y$ to John's left in $w$ " $\left(=d_{1}\right)$, "the $1^{\text {st }} y$ to John's right in $w$ " $\left.\left(=d_{1}\right)\right\rangle$,

〈"the $2^{\text {nd }} y$ to John's left in $w$ " $\left(=d_{2}\right)$, "the $2^{\text {nd }} y$ to John's right in $w$ " $\left(=d_{2}\right)$ ),

〈"the $3^{r d} y$ to John's left in $w$ " $\left(=d_{3}\right)$, "the $3^{r d} y$ to John's right in $w$ " $\left(=d_{3}\right)$ ),

$\left\langle\right.$ "the $7^{\text {th }} y$ to John's left in $w$ " $(=a)$, "the $7^{\text {th }} y$ to John's right in $w$ " $\left.\left(=d_{1}\right)\right\rangle$,

$\left\langle\right.$ "the $8^{\text {th }} y$ to John's left in $w$ " $(=b)$, "the $8^{\text {th }} y$ to John's right in $w$ " $\left(=d_{2}\right)$ ),

〈"the $9^{\text {th }} y$ to John's left in $w$ " $(=c)$, "the $9^{\text {th }} y$ to John's right in $w^{\prime}$ " $\left.\left.\left(=d_{3}\right)\right\rangle\right\}$

13 We also correctly predict that (5b) (John believes that every female student likes herself) can have the reading where John mistakes the individuals comprising pairs of the form $\langle x, x\rangle$, but cannot have a reading where John correctly identifies the individuals, but is mistaken about the identity function. In other words, (5b) cannot mean that John's thought is "Each of these individuals likes her aunt". 
To sum up, we have blocked the unattested reading of John believes that every female student likes her mother, but we are left with a theory that does not predict 'bound de re' pronouns.

We conclude that no 'de re' theory that relies solely on movement - of the scoping type or of the 'res'-movement type - can explain the 'bound de re' reading of (1). ${ }^{14}$ This is based on

i. the fact that LFs like (33) must be blocked so as to avoid overgeneration (and as a result only (31) is available as a 'res'-movement LF of (1)), and

ii. our conclusions from $§ 2.1$.

We therefore explore an alternative that makes no use of movement, of the scoping kind or of the 'res'-movement kind, but rather encodes guises - or acquaintance functions/relations - in the syntax. Since we won't be making any use of acquaintance with functions, from now on we make the simplifying assumption that individuals are only acquainted with individuals.

\section{The solution: concept-generator pronouns}

\subsection{Belief 'de re' without movement}

Percus \& Sauerland's (2003) concept-generator theory obviates the need for 'res'-movement: a 'de re' expression, according to that theory, is embedded in a larger noun phrase - as an argument of a pronominal element that denotes a concept-generator (to be defined below). For example, the 'de re'

14 It is worth pointing out that there actually is a way to account for 'bound de re' readings within 'res'-movement (see Sharvit 2011), but it requires some questionable assumptions and stipulations. Sharvit's (2011) analysis posits lexical items (OP, every*) that are not independently motivated. Translated to 'res'-movement, Sharvit's analysis works only if: (a) $O P$ in (i) applies to female-student- $w_{0}$ to yield a set of ordered pairs (whose first and second members are the same); (b) the trace $T_{5}$ in (i) is a variable over sets of ordered pairs; and (c) every* in (i) (as opposed to the standard every) applies to a set of pairs to yield something of type $\langle\langle e,\langle e, t\rangle\rangle, t\rangle$.

(i) John [believes- $w_{0}$ [fem-student- $\left.\left.w_{0} \mathrm{OP}\right]\right]$

$$
\begin{aligned}
& {\left[\lambda_{5} \lambda_{1} \text { [every* } T_{5}\right.} \\
& \left.\left.\quad\left[\lambda_{2} \lambda_{3}\left[t_{3} \text { likes- } w_{1} \text { her } 2 \text { mother- } w_{1}\right]\right]\right]\right]
\end{aligned}
$$

These assumptions are clearly ad-hoc, with the result that such a theory lacks any explanatory force. 
Bound 'de re' pronouns and the LFs of attitude reports

reading of John believes that Mary is French has the LF in (40), where the concept-generator is abstracted over in the scope of the attitude verb.

(40) John believe ${ }^{\mathrm{GC}}-w_{0}$

$$
\left[\lambda_{8} \lambda_{1}\left[\left[G_{8} \text { Mary }\right]-w_{1} \text { is French- } w_{1}\right]\right]
$$

This implies that the attitude verb takes only one internal argument - the argument corresponding to the embedded clause. As we now show, the theory provides an elegant solution to the problem of 'bound de re' readings.

The theory relies on the definition of 'suitable concept-generator' given in (42) (cf. Percus \& Sauerland 2003, fn. 16); the new semantics for believe is in (43). ${ }^{15}, 16$

(41) Concept-generators: $G$ is a concept-generator for individual $x$ in $w$ iff

a. $G$ is a function from individuals to individual concepts; and

b. $\operatorname{Dom}(G)=\left\{z \in D_{e}: x\right.$ is acquainted with $z$ in $\left.w\right\}$.

(42) Suitable concept-generators: A function $G$ of type $\langle e,\langle s, e\rangle\rangle$ is a suitable concept-generator for individual $x$ in $w$ iff

a. $G$ is a concept-generator for $x$ in $w$; and

15 This, too, is a simplification (see fns. 3 and 6). Percus \& Sauerland's definition of conceptgenerators (see their fn. 16) is closer to that in (i) (but see their fn. 2). Likewise, a more adequate semantics for believe ${ }^{\mathrm{GC}}$, one which captures 'de se' belief, is (ii).

(i) A function $G$ of type $\langle e,\langle s,\langle e, e\rangle\rangle\rangle$ is a suitable concept-generator for individual $x$ in $w$ only if there is a function $F$ from individuals to suitable acquaintance functions, such that

$$
\begin{array}{ll}
\operatorname{Dom}(G) \subseteq\left\{z \in D_{e}:\right. & \text { (a) } F_{z}(w)(x)=z \text {, and } \\
& \text { (b) } \left.\operatorname{Dox}_{x, w} \subseteq\left\{\left\langle w^{\prime}, x^{\prime}\right\rangle \in D_{s} \times D_{e}: F_{z}\left(w^{\prime}\right)\left(x^{\prime}\right)=G(z)\left(w^{\prime}\right)\left(x^{\prime}\right)\right\}\right\} .
\end{array}
$$

(ii) $\llbracket$ believe $\mathrm{GC}^{\mathrm{GC}} \rrbracket^{g}(w)\left(p_{\langle\langle e,\langle s,\langle e, e\rangle\rangle\rangle,\langle s,\langle e, t\rangle\rangle)}\right)(x)=1$ iff there is a suitable concept-generator $G$ for $x$ in $w$ such that

$$
\operatorname{Dox}_{x, w} \subseteq\left\{\left\langle w^{\prime}, x^{\prime}\right\rangle \in D_{s} \times D_{e}: p(G)\left(w^{\prime}\right)\left(x^{\prime}\right)=1\right\} .
$$

16 Concept-generators are bijections between the individuals an attitude holder is acquainted with and descriptions (i.e. individual concepts) the attitude holder has for those individuals. Accordingly, as Anand (2007) notes, they're similar to conceptual covers in the sense of Aloni (2005) (cf. also Aloni 2001). Pace Anand, there are differences. For instance, concept generators needn't return a value at the actual world. Another difference is the conceptgenerator theory is given an explicitly compositional formulation, the conceptual covers apparatus is not. 
b. there is a function $F$ from individuals to suitable acquaintance functions such that

$$
\begin{aligned}
\operatorname{Dom}(G) \subseteq\left\{z \in D_{e}: F_{z}(w)\right. & =z \text {, and } \\
& \left.\operatorname{Dox}_{x, w} \subseteq\left\{w^{\prime} \in D_{s}: F_{z}\left(w^{\prime}\right)=G(z)\left(w^{\prime}\right)\right\}\right\} .
\end{aligned}
$$

(43) For any $x$ in $D_{e}$, any $w$ in $D_{s}$, and any $p$ in $D_{\langle\langle e,\langle s, e\rangle\rangle,\langle s, t\rangle\rangle \text {, }}$

$$
\llbracket \text { believe }{ }^{\mathrm{GC}} \rrbracket^{g}(w)(p)(x)
$$

is defined only if for all (relevant) concept-generators $G$ suitable for $x$ in $w$

$$
\operatorname{Dox}_{x, w} \subseteq\left\{w^{\prime} \in D_{s}: p(G)\left(w^{\prime}\right) \text { is defined }\right\} .
$$

When defined, $\llbracket$ believe $\mathrm{GC}^{\mathrm{GC}} \rrbracket^{g}(w)(p)(x)=1$ iff there is a (relevant) concept-generator $G$ suitable for $x$ in $w$ such that

$$
\operatorname{Dox}_{x, w} \subseteq\left\{w^{\prime} \in D_{s}: p(G)\left(w^{\prime}\right)=1\right\} .
$$

In other words, concept-generators are functions that supply acquaintance functions, or guises, to the individuals in their domain. Since they are represented in the syntax, there is no need to make the 'res' a semantic argument of the attitude verb. Accordingly, 'de re' readings of John believes that Mary is French and John believes that every female student is French are generated as follows.

(44) a. John believe $\mathrm{GC}^{\mathrm{GC}} w_{0}$

$$
\text { [ } \left.\lambda_{8} \lambda_{1}\left[\left[G_{8} \text { Mary }\right]-w_{1} \text { is French- } w_{1}\right]\right]
$$

b. When defined, $\llbracket 44 \mathrm{a} \rrbracket^{\mathrm{g}}=1$ iff there is a suitable concept-generator $G$ for John in@ such that

$$
\operatorname{Dox}_{\text {John, }} \subseteq\left\{w \in D_{s}: G \text { (Mary) }(w) \text { is French in } w\right\} .
$$

(45) a. John believe ${ }^{\mathrm{GC}}-w_{0}$

$\left[\lambda_{8} \lambda_{1}\right.$ [every female student- $w_{0}$

$\left[\lambda_{2}\left[\left[G_{8} t_{2}\right]-w_{1}\right.\right.$ is French- $\left.\left.\left.\left.w_{1}\right]\right]\right]\right]$

b. When defined, $\llbracket 45 \mathrm{a} \rrbracket^{g}=1$ iff there is a suitable concept-generator $G$ for John in@ such that

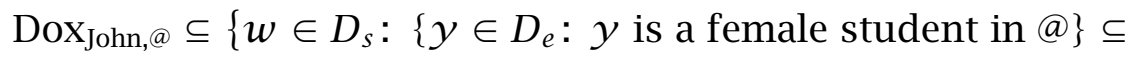

$$
\begin{aligned}
& \left\{y \in D_{e}: G(y)(w) \text { is French in } w\right\} \text {. }
\end{aligned}
$$

(There is a concept-generator $G$ suitable for John in @, such that at each of John's doxastic alternatives $w$ in @, every actual female student $y$ is such that $G(y)(w)$ is French in $w$.) 
Bound 'de re' pronouns and the LFs of attitude reports

Crucially, for any $x$, any relevant concept-generator $G$ such that $x \in \operatorname{Dom}(G)$, and any of John's doxastic alternatives $w$, it is possible that $\llbracket G_{8} \rrbracket^{g[8 \rightarrow G]}(x)(w) \neq$ $x$.

To account for 'bound de re' pronouns, we also assume: (a) that bound pronouns as well as traces can be arguments of concept-generator pronouns, as in (45a); ${ }^{17}$ and (b) that the semantics of believe is the type-flexible semantics in (46) (which allows LFs to contain as many concept-generator pronouns as there are 'res-es'), rather than the type-rigid semantics in (43). In (46), $n$ is the number of arguments of type $\langle e,\langle s, e\rangle\rangle$ that $p$ takes. ${ }^{18}$ In addition, $\operatorname{coN}(c)_{x, w, n}$ is a non-empty set of $n$-long sequences of concept-generators supplied by context $c$ that are suitable for $x$ in $w$ (a sequence of conceptgenerators $S$ is suitable for $x$ in $w$ when each member of $S$ is suitable for $x$ in $w)$.

(46) $\llbracket$ believe $\mathrm{FGC}^{c, g}(w)(p)(x)$ is defined only if for all $S\left(=\left\langle G_{1}^{S}, \ldots, G_{n}^{S}\right\rangle\right)$ in $\operatorname{CON}(c)_{x, w, n}$ such that

$$
\operatorname{Dox}_{x, w} \subseteq\left\{w^{\prime} \in D_{s}: p\left(G_{1}^{S}\right) \ldots\left(G_{n}^{S}\right)\left(w^{\prime}\right) \text { is defined }\right\} .
$$

When defined, $\llbracket$ believe $\mathrm{FGC}^{\mathrm{F}, g}(w)(p)(x)=1$ iff there is an $S\left(=\left\langle G_{1}^{S}, \ldots, G_{n}^{S}\right\rangle\right)$ in $\operatorname{CON}(c)_{x, w, n}$ such that

$$
\operatorname{Dox}_{x, w} \subseteq\left\{w^{\prime} \in D_{s}: p\left(G_{1}^{S}\right) \ldots\left(G_{n}^{S}\right)\left(w^{\prime}\right)=1\right\} .
$$

Accordingly, the 'simple bound' reading of (1) (with mother construed 'de dicto') can be obtained as in (47), where the two concept-generator pronouns are co-indexed; and the 'bound de re' reading (again, with mother construed 'de dicto') is obtained as in (48), where the two concept-generator-pronouns are not co-indexed.

(47) 'Simple bound' reading; the two concept-generators are co-indexed:

a. John believe $\mathrm{FGC}^{\mathrm{FG}} w_{0}$

$\left[\lambda_{8} \lambda_{1}\right.$ [every female student- $w_{0}$ $\left[\Lambda \mathrm{P} \lambda_{2}\left[\left[G_{8} t_{2}\right]-w_{1}\right.\right.$ likes- $w_{1}\left[G_{8}\right.$ her $\left.{ }_{2}\right]-w_{1}$ mother- $\left.\left.\left.\left.w_{1}\right]\right]\right]\right]$

17 Allowing concept generators to adjoin to 'de dicto' traces risks over-generation. See the appendix for discussion.

18 This is determined by the number of concept-generator abstractors in the LF:

i. if $n=0, p$ is of type $\langle s, t\rangle$;

ii. if $n>0$, then for any sequence of concept-generators $\left\langle X_{1}, X_{2}, \ldots, X_{n}\right\rangle, p\left(X_{1}\right)\left(X_{2}\right) \ldots\left(X_{n}\right)$ is of type $\langle s, t\rangle$ 
b. For any concept generator $G$ and any world $w$,

$$
\begin{aligned}
& \llbracket \Lambda \mathrm{P} \rrbracket^{c, g[8 \rightarrow G, 1 \rightarrow w]}= \\
& \quad \lambda x . G(x)(w) \text { likes MOther }(w)(G(x)(w)) \text { in } w .
\end{aligned}
$$

c. When defined, $\llbracket(47 \mathrm{a}) \rrbracket^{c, g}=1$ iff there is a $\langle G\rangle \in \operatorname{CON}(c)_{\text {John, } @, 1}$ such that

$$
\begin{aligned}
& \text { Dox John,@ }_{\text {J }} \subseteq\left\{w \in D_{s}:\left\{y \in D_{e}: y \text { is a female student in } @\right\} \subseteq\right. \\
&\left.\left\{y \in D_{e}: G(y)(w) \text { likes } \operatorname{MoTheR}(w)(G(y)(w)) \text { in } w\right\}\right\} .
\end{aligned}
$$

(48) 'Bound de re' reading; the two concept-generators are not co-indexed:

a. John believe $\mathrm{FGC}^{\mathrm{FG}} w_{0}$

$$
\begin{aligned}
& {\left[\lambda_{8} \lambda_{9} \lambda_{1} \text { [every female student- } w_{0}\right.} \\
& \left.\left.\quad\left[{ }_{\Lambda \mathrm{P}} \lambda_{2}\left[\left[G_{8} t_{2}\right]-w_{1} \text { likes- } w_{1}\left[G_{9} \text { her } 2\right]-w_{1} \text { mother- } w_{1}\right]\right]\right]\right]
\end{aligned}
$$

b. For any concept generators $G, H$ and any world $w$,

$$
\llbracket \Lambda \mathrm{P} \rrbracket^{c, g[8 \rightarrow G, 9 \rightarrow H, 1 \rightarrow w]}=
$$

$$
\lambda x . G(x)(w) \text { likes } \operatorname{Mother}(w)(H(x)(w)) \text { in } w .
$$

c. When defined, $\llbracket(48 \mathrm{a}) \rrbracket^{c, g}=1$ iff there is a $\langle G, H\rangle \in \operatorname{CON}(c)_{\text {John, }, 2}$ such that

$$
\begin{aligned}
& \text { Dox John,@ }_{\text {J }}\left\{w \in D_{s}:\left\{y \in D_{e}: y \text { is a female student in } @\right\} \subseteq\right. \\
&\left.\left\{y \in D_{e}: G(y)(w) \text { likes } \operatorname{motheR}(w)(H(y)(w)) \text { in } w\right\}\right\} .
\end{aligned}
$$

For the 'de re' ascription in (48) to be true, John needn't think anything of the form, " $x$ likes $x$ 's mother" (since $t_{2}$ and her 2 , though co-indexed, are arguments of distinct concept-generators).

Previous work already provides the essential ingredients of our proposal. However, to our knowledge, no one till now has shown that there are readings that only the concept-generator theory can generate. Let us elaborate on this point.

\subsection{What is borrowed, what is new}

First, notice an interesting technical difference between the 'res'-movement theory and the concept-generator theory. In practice, the number of 'res'denoting expressions can be bigger than one (as in John believed that Mary introduced Bill to Sue). On the 'res'-movement theory, we have to move all three 'res-es' (and ensure the type-flexibility of believere). On the conceptgenerator theory, we can work with one type-fixed believe $e^{\mathrm{GC}}$ (the one in (43)) 
Bound 'de re' pronouns and the LFs of attitude reports

as long as the 'res'-denoting expressions are not coreferential. This is because the domain of the concept-generator may already include all the individuals that the "subject" of the ascription is acquainted with.

(49) John [[[believe ${ }^{\mathrm{re}}-w_{0}$ Mary] Bill] Sue]

$$
\left[\lambda_{4} \lambda_{3} \lambda_{2} \lambda_{1}\left[t_{2} \text { introduced- } w_{1} t_{3} \text { to } t_{4}\right]\right]
$$

(50) John believe ${ }^{\mathrm{GC}}-w_{0}$

$$
\left[\lambda_{8} \lambda_{1}\left[\left[G_{8} \text { Mary }\right]-w_{1} \text { introduced- } w_{1}\left[G_{8} \text { Bill }\right]-w_{1} \text { to }\left[G_{8} \text { Sue }-w_{1}\right]\right]\right.
$$

However, as noted in Anand (2006) (see also Percus 2010), if the 'res-es' are co-referential, even the concept-generator analysis requires a type-flexible believe. (51) has a reading according to which the hurter and hurtee are not the same, in Ralph's mind.

(51) Ralph believes that Ortcutt hurt himself.

(52) Ralph believe ${ }^{\mathrm{FGC}}-w_{0}$

$$
\left[\lambda_{8} \lambda_{9} \lambda_{1}\left[\left[G_{8} \text { Ortcutt }\right]-w_{1} \text { hurt- } w_{1}\left[G_{9} \text { himself }{ }_{3}\right]-w_{1}\right]\right]
$$

(where $\llbracket$ himself $\rrbracket_{3} \rrbracket^{g}=$ Ortcutt)

But since (51) doesn't necessarily contain a bound variable, all it shows is that if we are to adopt the concept-generator theory, we have to adopt a typeflexible version of believe. It doesn't show that the concept-generator theory has any semantic advantage over 'res'-movement, as the relevant reading of (51) is easily accounted for with 'res'-movement:

(53) Ralph [[believe ${ }^{\mathrm{re}}-w_{0}$ himself $\left._{3}\right]$ Ortcutt]

$$
\left[\lambda_{2} \lambda_{3} \lambda_{1}\left[t_{3} \text { hurt- } w_{1} t_{2}\right]\right]
$$

Percus \& Sauerland (2003), on the other hand, make the point that bound pronouns can be arguments of concept-generator variables. But the examples they discuss involve pronouns bound by quantifiers that appear above the attitude verb, as in (54).

(54) Every candidate believes that he will win.

(Every candidate $x$, pointing at a picture of $x$, without necessarily realizing that it is a picture of $x$ : "This guy will win")

Again, (54) only shows that if the concept-generator theory is to be adopted, it needs to allow concept-generators to apply to bound pronouns. What (54) crucially does not show is that the concept-generator theory has any advantage over 'res'-movement. 
(55) a. Concept-generator analysis:

every candidate- $w_{0}$

$$
\begin{aligned}
& {\left[\lambda _ { 4 } \left[t_{4} \text { believe }{ }^{\mathrm{GC}}-w_{0}\right.\right.} \\
& \left.\left.\quad\left[\lambda_{9} \lambda_{1}\left[\left[G_{9} \text { he }{ }_{4}\right]-w_{1} \text { win- } w_{1}\right]\right]\right]\right]
\end{aligned}
$$

\section{b. 'Res'-movement analysis}

every candidate- $w_{0}$

$$
\begin{array}{r}
{\left[\lambda _ { 4 } \left[t_{4}\left[\text { believere }-w_{0} \text { he }_{4}\right]\right.\right.} \\
\left.\left.\left[\lambda_{4} \lambda_{1}\left[t_{4} \text { win }-w_{1}\right]\right]\right]\right]
\end{array}
$$

Crucially, only those examples where the pronoun is bound by an operator situated "below" believe show the superiority of the concept-generator theory (from a semantic point of view): as we saw, these cases are not covered by 'res'-movement.

It is worth pointing out that the concept-generator theory is not the only theory that offers a compositional semantics of 'de re' ascriptions without movement. In fact, within Lewis's counterpart theory (Lewis 1979), a simple LF such as (56) (for John believes that Mary is French) can yield the desired reading ((56) itself is, of course, not taken directly from Lewis's work, but is rather an attempt to implement his ideas within a syntactic framework).

\section{(56) John- $w_{0}$ believes- $w_{0}\left[\lambda_{2}\left[\right.\right.$ Mary- $w_{2}$ is French- $\left.\left.w_{2}\right]\right]$}

Mary- $w_{2}$ does not denote the "real" Mary, but rather a counterpart of Mary in $\llbracket w_{2} \rrbracket^{g[2 \rightarrow w]}$, for any $w$ in Dox John,@. In attitude reports, the counterpart relation is mediated by a contextually-supplied acquaintance relation - in Lewis's terms, “counterpart by acquaintance”. On this view, the 'res' is not a syntactic argument of believe, and no movement is necessary. Importantly, the counterpart-based LFs, unless augmented with a counterpart-selecting mechanism, fail with multiple co-referential 'res-es' in general, and 'bound de re' pronouns in particular. It is possible that counterpart selection is done in the semantics, rather than the syntax (in which case our claim that the syntax must be "transparent" - i.e., that counterpart selection is done by pronominal elements - might be too strong). We do not consider this option to be radically different from what we are proposing, or, for that matter, from what Percus \& Sauerland propose. ${ }^{19}$

This concludes the discussion of our main claim regarding 'bound de re' pronouns. In the next section we try to think more seriously about the quantificational force of believe. This issue raises more problems than solutions,

19 We thank Angelika Kratzer and Paolo Santorio for their input on this issue. 
Bound 'de re' pronouns and the LFs of attitude reports

but we think that it is nevertheless worth discussing, because it is intimately tied to how ascriptions with quantificational binders in the embedded clause are interpreted in multiple-guise scenarios (which constructions motivate the existence of 'bound de re' pronouns in the first place).

\section{Believe as a universal quantifier over concept-generators}

\subsection{The problem of negative quantifiers}

Let us go back to the examples that motivated the Kaplan/Lewis/Cresswell \& von Stechow view of "relational" believe.

(57) a. Ralph believes that Ortcutt is a spy and, at the same time, he believes that Ortcutt is not a spy.

b. John believes that Mary is French and, at the same time, he believes that Mary is German.

These examples are predicted to be well-formed both by the "relational" theories of believe and by the concept-generator theory, because the acquaintance functions/concept-generators are introduced existentially. The type-flexible semantics for believe is repeated in (58).

(58) If defined, $\llbracket$ believe $\mathrm{FGC}^{c, g}(w)(p)(x)=1$ iff there is an $S$

$\left(=\left\langle G_{1}^{S}, \ldots, G_{n}^{S}\right\rangle\right)$ in $\operatorname{CON}(c)_{x, w, n}$ such that

$$
\operatorname{Dox}_{x, w} \subseteq\left\{w^{\prime} \in D_{s}: p\left(G_{1}^{S}\right) \ldots\left(G_{n}^{S}\right)\left(w^{\prime}\right)=1\right\} .
$$

But there is reason to believe that "existential" believe is sometimes too weak. $^{20}$ Let us discuss in more detail the possibility that believe sometimes quantifies universally over acquaintance functions/concept-generators. Specifically, universal quantification seems to be invoked when the quantifier binding a 'de re' pronoun/trace is downward-entailing. Consider in this regard (59a) and (59b): the former is acceptable in scenario (6oa) as well as (6ob); the latter is acceptable only in (6oc).

(59) a. John believes that every female student is French.

20 Our criticism of the "existential" theory will also apply to Aloni's (2005) quantifier-less theory of 'de re' ascription. As mentioned in fn. 16, concept-generators can be thought of as conceptual covers. So a quantifier-less concept-generator theory will be equivalent to Aloni's quantifier-less conceptual-covers theory. We show that you often need to derive stronger truth conditions than either a wide-scoping existential-style analysis or a quantifierless analysis can produce. For simplicity, we limit our remarks to "traditional" existential theories. 
b. John believes that no female student is French.

(6o) John looks at three pairs of pictures of actual female students - two pictures of Mary, two pictures of Sally, two pictures of Betty - and doesn't realize

i. that they're students (in fact, he thinks they're professors), and

ii. that the same person is depicted in each pair.

He says:

a. "The professor in red [who happens to be Mary], the professor in yellow [who happens to be Sally] and the professor in green [who happens to be Betty] are all French.

The other three - including the professor in blue [who also happens to be Mary], the professor in gray [who also happens to be Sally] and the professor in pink [who also happens to be Betty] - are Italian."

b. "The professor in red [who happens to be Mary], the professor in yellow [who happens to be Sally] and the professor in green [who happens to be Betty] are all French.

The other three - including the professor in blue [who also happens to be Mary], the professor in gray [who also happens to be Sally] and the professor in pink [who also happens to be Betty] - are also French."

c. "The professor in red [who happens to be Mary], the professor in yellow [who happens to be Sally] and the professor in green [who happens to be Betty] are all Italian.

The other three - including the professor in blue [who also happens to be Mary], the professor in gray [who also happens to be Sally] and the professor in pink [who also happens to be Betty] - are also Italian."

However, given (58) we expect (59b) to be acceptable in (6oa) as well (see (62b)). That this fails to obtain (that is to say, that the right predictions are made only regarding (59a); see (61b)) suggests that believe has a "universal" reading, as in (63).

a. John believe $\mathrm{F}^{\mathrm{FGC}}-w_{0}$

$\left[\lambda_{8} \lambda_{1}\right.$ [every female-student- $w_{0}$

$\left[\lambda_{2}\left[\left[G_{8} t_{2}\right]-w_{1}\right.\right.$ is French- $\left.\left.\left.\left.w_{1}\right]\right]\right]\right]$ 
Bound 'de re' pronouns and the LFs of attitude reports

b. When defined, $\llbracket(61 a) \rrbracket^{c, g}=1$ iff there is a relevant conceptgenerator $G$ such that

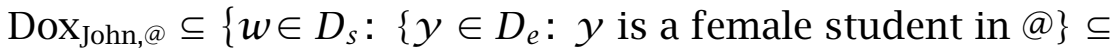

$$
\left\{y \in D_{e}: G(y)(w) \text { is French in } w\right\} \text {. }
$$

(62) a. John believe $\mathrm{FGC}^{\mathrm{F}}-w_{0}$

$$
\left[\lambda_{8} \lambda_{1} \text { [no female-student- } w_{0}\right.
$$

$\left[\lambda_{2}\left[\left[G_{8} t_{2}\right]-w_{1}\right.\right.$ is French- $\left.\left.\left.\left.w_{1}\right]\right]\right]\right]$

b. When defined, $\llbracket(62 a) \rrbracket^{c, g}=1$ iff there is a relevant conceptgenerator $G$ such that

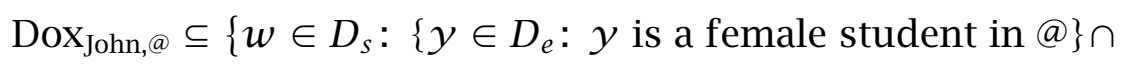

$$
\left.\left\{y \in D_{e}: G(y)(w) \text { is French in } w\right\}=\emptyset\right\} \text {. }
$$

(63) $\llbracket$ believe $^{\mathrm{U}} \rrbracket^{c, g}(w)(p)(x)$ is defined only if for all $S\left(=\left\langle G_{1}^{S}, \ldots, G_{n}^{S}\right\rangle\right)$ in $\operatorname{coN}(c)_{x, w, n}$,

$$
\operatorname{Dox}_{x, w} \subseteq\left\{w^{\prime} \in D_{s}: p\left(G_{1}^{S}\right) \ldots\left(G_{n}^{S}\right)\left(w^{\prime}\right) \text { is defined }\right\} .
$$

When defined, $\llbracket$ believe $^{\mathrm{U}} \rrbracket^{c, g}(w)(p)(x)=1$ iff for all $S\left(=\left\langle G_{1}^{S}, \ldots, G_{n}^{S}\right\rangle\right)$ in $\operatorname{CON}(c)_{x, w, n}$,

$$
\operatorname{Dox}_{x, w} \subseteq\left\{w^{\prime} \in D_{s}: p\left(G_{1}^{S}\right) \ldots\left(G_{n}^{S}\right)\left(w^{\prime}\right)=1\right\} .
$$

Suppose $\sigma_{1}$ is a concept-generator that yields "the professor in red" for Mary, "the professor in yellow" for Sally and "the professor in green" for Betty; and $\sigma_{2}$ is a concept-generator that yields "the professor in blue" for Mary, "the professor in gray" for Sally and "the professor in pink" for Betty (so $\operatorname{CON}(c)_{\text {John,@,1 }}=\left\{\sigma_{1}, \sigma_{2}\right\}$ ). The judgments reported for (59b) are predicted by (63):

(64) a. John believes ${ }^{\mathrm{U}}-w_{0}$

$$
\left[\lambda_{8} \lambda_{1} \text { [no-female-student- } w_{0}\right.
$$

$\left[\lambda_{2}\left[\left[G_{8} t_{2}\right]-w_{1}\right.\right.$ is French- $\left.\left.\left.\left.w_{1}\right]\right]\right]\right]$

b. When defined, $\llbracket(64 \mathrm{a}) \rrbracket^{c, g}=1$ iff

$$
\begin{aligned}
\operatorname{Dox}_{\text {John }, @} \subseteq\left\{w \in D_{s}:\left\{y \in D_{e}: y \text { is a female student in } @\right\} \cap\right. \\
\left.\left\{y \in D_{e}: \sigma_{1}(y)(w) \text { or } \sigma_{2}(y)(w) \text { is French in } w\right\}=\emptyset\right\} .
\end{aligned}
$$

(For every concept generator $G \in \operatorname{CON}(c)_{\text {John,@,1 }}$ and all of John's doxastic alternatives $w$ in @, no actual female student $y$ is such that $G(y)(w)$ is French in $w$.) 
On the other hand, if $\operatorname{CON}(c)_{\mathrm{John}, @, 1}=\left\{\sigma_{1}, \sigma_{2}\right\}$, the judgments reported for (59a) are predicted by (58); (63) imposes truth conditions that are too strong for a scenario like (6oa): since for each female student $x$, each of John's doxastic alternatives $w^{\prime}$ is such that $\sigma_{2}(x)\left(w^{\prime}\right)$ fails in $w^{\prime}$ to be French, believe $^{\mathrm{U}}$ plus $\operatorname{CON}(c)_{\mathrm{John}, @, 1}=\left\{\sigma_{1}, \sigma_{2}\right\}$ incorrectly predicts that (59a) should be false.

An anonymous reviewer calls our attention to another case where universal believe makes predictions that are not quite right. Suppose there are three American students who like to dress up as men and walk around town playing tricks on people. On day 1 , the three students meet John and pretend (successfully) to be Italian. On day 2, they dress in another disguise and again meet John, but this time they pretend (again successfully) to be French. John doesn't realize that the students are students or American, nor does he identify the people he met on day 1 with the people he met on day 2. Then the following ascriptions both seem to be true:

(65) a. On day 1, John believed that none of the three female students was French.

b. On day 2, John believed that none of the three female students was Italian.

This case shows that if universal quantification is invoked to explain 'de re' readings with negative quantifiers, it needs to be restricted to salient sets of concept generators. In example (65a), the salient concept generator(s) will map the female students to the people that John met on day 1, and in example (65b) the salient concept generator(s) will map the female students, naturally, to the people that John met on day 2.

Let us therefore assume that both versions of believe are available - or, alternatively, that the grammar contains only believe $e^{\mathrm{U}}$, but $\operatorname{CON}(c)_{x, w, n}$ can be "shrunk" to a set possibly containing just one sequence of conceptgenerators. For some reason (that we do not understand) the universal semantics is often preferred when the 'de re' quantifier is downward-entailing. Alternatively, the singleton shrinking of $\operatorname{coN}(c)_{x, w, n}$ only happens when the concept-generator's argument isn't bound by a downward-entailing quantifier. (Note that this isn't simply a matter of the bound 'de re' pronoun being in a downward-entailing environment; e.g. a natural reading of no one believes Ralph is smart entails that no one believes of Ralph under any guise that he is smart.) The asymmetry is further evidenced by the contrast between the following sentences, which contain 'bound de re' pronouns. As before, John is 
Bound 'de re' pronouns and the LFs of attitude reports

looking at the pairs $\langle$ Mary, Mary $\rangle$, $\langle$ Sally, Sally $\rangle$, and $\langle$ Betty, Betty $\rangle$-i.e. pairs of photographs.

(66) a. John believes that every female student likes her friend.

b. John believes that no female student likes her friend.

As we already saw, intuitions regarding (66a) are explained by "existential" believe $^{\mathrm{FGC}}$. But notice that intuitions regarding (66b) are not: the truth of (66b) requires that, in John's "mind", it isn't just the case that one member of each pair doesn't like the friend of the other member, but rather, it must be that neither of them likes the friend of the other. This is predicted by believe ${ }^{\mathrm{U}}$, assuming $\operatorname{CON}(c)_{\mathrm{John}, \varrho_{, 2}}=\left\{\left\langle\sigma_{1}, \sigma_{2}\right\rangle,\left\langle\sigma_{2}, \sigma_{1}\right\rangle\right\}$.

(67) a. John believe $\mathrm{U}^{\mathrm{U}}-w_{0}$

$\left[\lambda_{8} \lambda_{9} \lambda_{1}\right.$ [no female student- $w_{0}$

$\left[\lambda_{2}\left[\left[G_{8} t_{2}\right]-w_{1}\right.\right.$ likes- $w_{1}\left[G_{9}\right.$ her 2$]-w_{1}$ friend- $\left.\left.\left.\left.w_{1}\right]\right]\right]\right]$

b. When defined, $\llbracket(67 \mathrm{a}) \rrbracket^{c, g}=1$ iff for every pair of concept-generators $\langle G, H\rangle$ in $\operatorname{CON}(c)_{\mathrm{John}, @, 2}$,

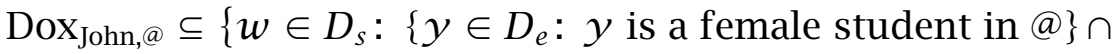

$$
\begin{aligned}
& \left.\left\{y \in D_{e}: G(y)(w) \text { likes } \operatorname{FRIEND}(w)(H(y)(w)) \text { in } w\right\}=\emptyset\right\} \text {. }
\end{aligned}
$$

(For every pair of concept-generators $\langle G, H\rangle$ in $\operatorname{CON}(c)_{\text {John,@,2, and }}$ all of John's doxastic alternatives $w$ in @, no actual female student $y$ is such that $G(y)(w)$ likes in $w H(y)(w)$ 's friend in $w$.)

It should be noted that even when the 'de re' quantifier is downward-entailing, the existential version of believe is sometimes chosen. One case is when the context imposes (lexical or non-lexical) presuppositions that make it impossible to implement "universal" believe. An example that comes to mind is John believes that no female student voted for her opponent: if, in John's mind, not every relevant individual is a candidate, then he cannot entertain the "reciprocal" belief predicted by "universal" believe ${ }^{\mathrm{U}}$, but he may still be able to entertain the "non-reciprocal" belief predicted by "existential" believe $^{\mathrm{FGC}}$ (though again, this could result from coupling "universal" believe with an appropriately restricted $\operatorname{coN}(c)_{x, w, n}$, i.e. one whose second member only ever outputs candidates). 


\subsection{Additional data}

More evidence for universal quantification is provided by only-constructions, as in (68), in a scenario where John is looking at pairs of pictures of all relevant women.

(68) John believes that only Mary is French.

The first thing to note for this case is that the predictions of existential believe are spectacularly wrong. Say the relevant domain of individuals is \{Mary, Sally\}. Then, given a standard semantics for only (and assuming that the presuppositions triggered by only can be accommodated in the scope of the attitude à la Heim 1992), (68) is predicted to be true if John believes 'de re' of Mary that she is French, and John believes 'de re' of Sally that she isn't. These truth conditions are satisfied even in a multiple-guise scenario where John has totally parallel beliefs about Mary and Sally - i.e. he believes that Mary (qua A) is French, Mary (qua B) isn't French, Sally (qua C) is French, and Sally (qua D) isn't French.

a. John believe ${ }^{\mathrm{FGC}}-w_{0}$

$$
\left[\lambda_{8} \lambda_{1}\right. \text { [only MARYF }
$$

$\left[\lambda_{2}\left[\left[G_{8} t_{2}\right]-w_{1}\right.\right.$ is French- $\left.\left.\left.\left.w_{1}\right]\right]\right]\right]$

b. When defined, $\llbracket(69 a) \rrbracket^{c, g}=1$ iff there is a relevant conceptgenerator $G$ such that

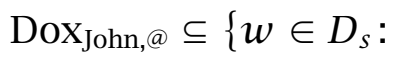

$$
\begin{aligned}
& \left\{y \in D_{e}: G(y)(w) \text { is French in } w\right\}=\{\text { Mary }\} \text {. }
\end{aligned}
$$

Relative to our scenario, the truth of (69) is witnessed by a $G$ such that for

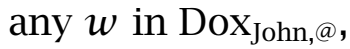

$$
G(\operatorname{Mary})(w)=A
$$

(French, in John's mind, though Mary-under-guise-B isn't), and

$$
G(\text { Sally })(w)=D
$$

(Not French, in John's mind, though Sally-under-guise-C is). But certainly (68) isn't true here!

This out of the way, we return to motivating the usefulness of existential quantification over concept-generators. That (68) is false in a parallel multiple-guise scenario is an extremely robust judgment, but what exactly are its truth conditions? This turns out to be a far subtler matter. Our consultants require that for every $x$ distinct from Mary, all the relevant guises under 
Bound 'de re' pronouns and the LFs of attitude reports

which $x$ appears must be non-French; but for Mary herself, it suffices that just one of the "Mary's" be French. In other words, the sentence is judged true in scenario (70a) and false in scenario (7ob) by all speakers, as predicted by universal believe ${ }^{\mathrm{U}}$. However, our consultants still judge it true in the scenario described in (7Oc), which suggests that the presupposition contributed by only is evaluated relative to existential believe, suggesting the lexical entry in $(71)^{21}$

(70) John looks at two pairs of pictures - two pictures of Mary and two pictures of Sally - and doesn't realize that the same person is depicted in each pair. He says:

a. "The woman in red [who happens to be Mary] is French and the woman in blue [who also happens to be Mary] is French. The other two are Italian.”

b. "The woman in gray [who happens to be Sally] is Italian. The other three - including the woman in yellow [who also happens to be Sally] - are French."

c. "The woman in red [who happens to be Mary] is French. The other three - including the woman in blue [who also happens to be Mary] - are Italian.”

(71) $\llbracket$ believe $\mathrm{U}^{\prime} \rrbracket^{c, g}(w)(p)(x)$ is defined only if there is an $S\left(=\left\langle G_{1}^{S}, \ldots, G_{n}^{S}\right\rangle\right)$ in $\operatorname{CON}(c)_{x, w, n}$ such that

$$
\operatorname{Dox}_{x, w} \subseteq\left\{w^{\prime} \in D_{s}: p\left(G_{1}^{S}\right) \ldots\left(G_{n}^{S}\right)\left(w^{\prime}\right) \text { is defined }\right\} .
$$

21 Even if we could derive satisfactory truth conditions without universal quantification, by making certain assumptions about the interaction of concept-generators with focus (cf. (i) below, which embeds a concept-generator under an F-mark), (a) we'd still need to somehow avoid generating the incorrect truth conditions in (69), and (b) 'bound de re' readings of constructions like John believes that only Mary likes her friend would remain problematic. An LF like (ii) doesn't have the focused material binding her 2 (nor could it, cf. the appendix), so its truth conditions are necessarily not those of the 'bound de re' reading.

(i) John believe $\mathrm{FGC}^{\mathrm{FG}} w_{0}$

$\left[\lambda_{8} \lambda_{1}\right.$ [only $\left[G_{8} \text { Mary }\right]_{\mathrm{F}}-w_{1}$ is French- $\left.\left.w_{1}\right]\right]$

(ii) John believe $\mathrm{FGC}_{-} w_{0}$

$\left[\lambda_{9} \lambda_{8} \lambda_{1}\right.$ [only [Mary

$\left[\lambda_{2}\left[G_{8} t_{2}\right]_{\mathrm{F}}-w_{1}\right.$ likes- $w_{1}\left[G_{9}\right.$ her 2$]-w_{1}$ friend- $\left.\left.\left.\left.w_{1}\right]\right]\right]\right]$ 
When defined, $\llbracket$ believe $^{\mathrm{U}^{\prime}} \rrbracket^{c, g}(w)(p)(x)=1$ iff for all $S\left(=\left\langle G_{1}^{S}, \ldots, G_{n}^{S}\right\rangle\right)$ in $\operatorname{CON}(c)_{x, w, n}$,

$$
\operatorname{Dox}_{x, w} \subseteq\left\{w^{\prime} \in D_{s}: p\left(G_{1}^{S}\right) \ldots\left(G_{n}^{S}\right)\left(w^{\prime}\right)=1\right\} .
$$

On the other hand, for other cases the existentially quantified definedness condition is arguably too weak. Consider Mary thinks only John remembers Steve. Even on the 'de re' reading, it should presuppose that Mary thinks of each alternative to John that he is alive. But the definedness condition is consistent with Mary failing to think so. We have to leave this issue open.

We've argued that the facts may motivate a (partially) "universal" instantiation of believe. Another conceivable proposal allows the existential quantifier over sequences of concept-generators to take non-maximal scope (i.e., below no female student in (59b) or only Mary in (68)). ${ }^{22}$ This is an appealing account in some respects, but it faces a major difficulty: belief in a singular proposition (speaking loosely) is usually considered a necessary feature of 'de re' belief. In other words, for John to have a 'de re' belief about someone, there must be some $x$ of whom John believes so-and-so. But if concept-generators can vary across belief alternatives, 'de re' belief is dissociated from singular belief: a sentence like John believes Ortcutt killed Ralph is mapped to True if, for each of John's belief alternatives $w$, there is some concept-generator $G$ such that $G$ (Ortcutt) $(w)$ killed Ralph in $w$. This seems to be an undesirable outcome: if John thinks, "it was either A or B who killed Ralph", where A, B, an C are guises under which John knows Ortcutt, and where John incorrectly believes A, B, and C to be different people, speakers hesitate to judge John believes Ortcutt killed Ralph true (similarly for the singular-belief-ascribing there's someone who John believes killed Ralph).

On the other hand, consider (72a) in a context where John sees Mary on three different occasions (and fails to recognize her each time): there is one person who admires her on the first occasion, and there is another person who admires her on the other two occasions. Relative to this scenario, (72a) seems relatively well-formed, which may suggest that our semantics should allow acquaintance functions/concept-generators to vary under exactly two people. But if narrow existential closure over (sequences of) concept-generators is out, how are the correct truth conditions derived? One option is admitting parameterized concept-generators (cf. Skolemized choice functions) as in (72b). This move allows acquaintance functions/concept-generators to vary with admirers while avoiding the over-generation associated with free exis-

22 Thanks to Nicholas Fleisher and Ezra Keshet for discussion of this and related points. 
Bound 'de re' pronouns and the LFs of attitude reports

tential closure over concept-generators. (Note that $\operatorname{coN}(c)_{x, w, n}$ is now a set of parametrized concept generators.)

(72) a. John believes that Mary is admired by exactly two people.

b. For every $\mathfrak{G}_{\langle e,\langle e,\langle s, e\rangle\rangle\rangle}$ in $\operatorname{CON}(c)_{\text {John,@, } 1 \text {, }}$

$$
\begin{aligned}
& \text { Dox John, }_{\text {J }} \subseteq\left\{w \in D_{s}:\right. \\
&\left.\mid\left\{z \in D_{e}: z \text { admires } \mathscr{G}_{z}(\operatorname{Mary})(w) \text { in } w\right\} \mid=2\right\} .
\end{aligned}
$$

But a familiar problem from the Skolemized choice functions literature bedevils us here. The original problem, noticed by Chierchia (2001) and discussed by Kratzer (2003), Schlenker (2006), Solomon (2011), a.o., is that unattested readings arise when a Skolemized choice function is bound by a non-distributive quantifier such as no one or exactly two students. Take the LF in (73), corresponding to no student read a (certain) book. If $f$ is resolved to the function mapping each student $x$ to (a function from the set of books to) the single book $x$ didn't read, then no student read a (certain) book is predicted to have truth conditions to the effect that no student read every book, a meaning it lacks (though see Kratzer 2003 for another view).

(73) No student $x$ read $f_{x}$ (book)

Let's see how this makes trouble for our proposal. Suppose, for instance, that at each of John's doxastic alternatives, there's 2 individuals A and B corresponding to the actual Mary (i.e., assume a classic double-vision scenario). Now assume that at each of John's doxastic alternatives there's 5 relevant individuals in the denotation of people. If John thinks each of those 5 individuals admires A and that each of them doesn't admire B, then (72a) is intuitively quite false. Yet if $\operatorname{CON}(c)_{\text {John,@,1 }}$ contains just one Skolemized concept-generator $\mathfrak{6}$ such that at each of John's doxastic alternatives $w$,

$$
\begin{gathered}
\left|\left\{x: \mathfrak{G}_{x}(\operatorname{Mary})(w)=\mathrm{A}\right\}\right|=2, \quad \text { and } \\
\left|\left\{x: \mathfrak{G}_{x}(\operatorname{Mary})(w)=\mathrm{B}\right\}\right|=3 .
\end{gathered}
$$

(assuming that $\operatorname{Dom}(\mathfrak{G})$ is just the relevant 5 individuals), the truth conditions in (72b) will be satisfied. Now, for this to really trouble us, we'd have to get a grip on why this sort of Skolemized concept-generator would make it into $\operatorname{CON}(c)_{\text {John,@,1 }}$ in the first place (cf. e.g. Kratzer's 2003 reply to Chierchia 2001 or Schlenker 2006 on "natural functions"). Yet insofar as recent work (Solomon 2011) seems to suggest that natural, empirically successful constraints on Skolemized choice functions are difficult to formulate, the 
Skolemized concept-generator theory must be seen as a very preliminary proposal.

\section{Summary}

'Bound de re' readings of pronouns support a non-relational semantics for believe, one which has a single, "clausal", internal argument and which quantifies over concept-generators. In addition, the kinds of scenarios required to evaluate 'bound de re' readings - scenarios involving beliefs about individuals in the domain of an attitude-embedded quantifier whom the attitude holder knows in multiple ways (possibly without identifying that these guises actually correspond to a single individual) - lead to the conclusion that believe at least sometimes quantifies universally, rather than existentially, over concept-generators.

\section{Appendix: 'De dicto/de re' and iterated belief reports}

An area of potential over-generation in the concept-generator theory bears mentioning. We must somehow rule out configurations where (in simple, noniterated belief reports) concept-generators are adjoined to traces/pronouns bound by 'de dicto' expressions; e.g. the system shouldn't generate 'de re' ascriptions about unicorns or whoever a misinformed attitude holder takes the king of France to be (though we'll refine this characterization shortly). The first of these (unicorns) might follow from how concept-generators are defined - in particular the stipulation that the attitude holder be acquainted with each 'res' in the domain of the concept-generator. However, the second (the king of France) certainly does not. After all, a deranged William Daley (Barack Obama's chief of staff) might come to believe that Barack Obama, whom he works for and is very much acquainted with, is ('de dicto') the king of France. But Daley might also unwittingly know Obama under two guises A and $\mathrm{B}$; he might think that A is the upstanding Barack Obama (for Daley, the king of France), and that B is a notorious spy. Daley thinks there's a unique king of France and that the king of France is a spy doesn't have any true readings here, but so long as there's a $G \in \operatorname{CON}(c)_{\text {Daley,@,1 }}$ such that for any 
Bound 'de re' pronouns and the LFs of attitude reports

$w \in$ Dox $_{\text {Daley,@ }}, G($ Obama $)(w)^{23}=$ the (relevant) spy in $w,(74)$ evaluates to True. ${ }^{24}$

(74) «Daley believe- $w_{0}$ $\left[\lambda_{8} \lambda_{1}\left[\left[G_{8}\right.\right.\right.$ KoF- $\left.-w_{1}\right]-w_{1}$ is a spy- $\left.\left.w_{1}\right]\right] \rrbracket^{c, g}=1$ iff

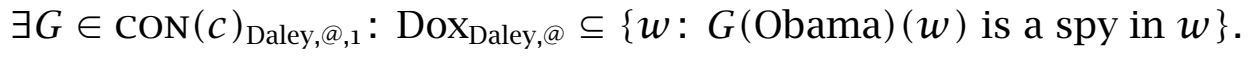

Iterated belief reports show that this is a somewhat subtle problem. Say Daley still thinks there's a unique king of France (Obama), but that he believes Hillary Clinton is in a Quinean double-vision scenario - i.e. Daley thinks Clinton knows the king of France (i.e. Obama) under two different guises: A and B. Daley thinks Clinton believes A is a spy and B isn't. Then, for instance, Daley believes there's a unique king of France and that Clinton thinks the king of France is a spy is true, presumably due to the following LF and truth conditions: ${ }^{25}$

23 Equivalent, given what we know about Daley's beliefs, to $G(\operatorname{KoF}(w))(w)$.

24 We should also rule out some configurations where concept-generators are sisters of syntactically 'de se' traces/pronouns (that is, traces/pronouns bound by the 'de se' abstractor,

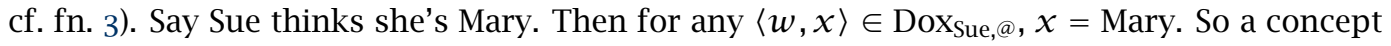
generator adjoined to a 'de se' pronoun (like in (i) below, with $\lambda_{i}$ a 'de se' abstractor operator which allows the complement clause to denote something in the domain of the 'de se' attitude verb, cf. fns. 1 and 5) supplies a guise for Mary rather than one for Sue. Now say an actual description of Mary is the woman living at 17 Quincy, and, moreover, that Sue is acquainted with Mary and that she believes 'de dicto' that the woman living at 17 Quincy is a total bore - though, naturally, Sue thinks, "Unlike the woman living at 17 Quincy, I'm the life of the party". In other words, Sue doesn't think "I/Mary live(s) at 17 Quincy". Does $S u e_{i}$ believes $s_{i}$ 's a bore have any true readings here? Though the answer seems to be no, the $\mathrm{LF}$ in (i) (where $\lambda_{i}$ is a 'de se' abstractor operator which allows the complement clause to denote something in the domain of the attitude verb, cf. fns. 3 and 6) is mapped to True.

(i) $\llbracket$ Sue believes- $w_{0}\left[\lambda_{8} \lambda_{1} \lambda_{i}\left[\left[\left[G_{8}\right.\right.\right.\right.$ she $\left.\left.{ }_{i}\right]-w_{1}\right]-x_{i}$ is a bore- $\left.\left.w_{1}\right]\right] \rrbracket^{c, g}=1$ iff

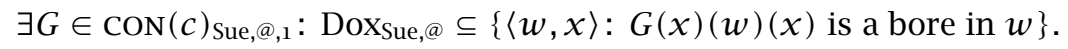

25 Similarly, Sue thinks John believes she's a total bore has a reading where Sue's belief is 'de se', but she's ascribing a 'de re' belief about herself to John - i.e. she might think John knows her under two guises. Presumably the LF underlying this reading has to look something like (ii). So ruling out problematic ‘de se/de re’ LFs can't simply be a matter of forbidding concept-generators from being adjoined to 'de se' pronouns/traces: 
(75) 『Daley believes- $w_{0}$

$$
\begin{aligned}
& {\left[\lambda_{1} \text { [Clinton thinks- } w_{1}\right.} \\
& \left.\left.\left.\left[\lambda_{8} \lambda_{2}\left[\left[G_{8} \mathrm{KoF}-w_{1}\right]-w_{2} \text { is a spy- } w_{2}\right]\right]\right]\right]\right]^{c, g}=1 \text { iff } \\
& \text { DoX }_{\text {Daley }, @} \subseteq\left\{w: \exists G \in \operatorname{CON}(c)_{\text {Clinton }, w, 1}\right. \text { : } \\
& \text { Dox } \left._{\text {Clinton, } w} \subseteq\left\{w^{\prime}: G \text { (Obama) }\left(w^{\prime}\right) \text { is a spy in } w^{\prime}\right\}\right\} \text {. }
\end{aligned}
$$

Thus, it only makes sense to talk about the 'de dicto'/'de re' distinction in relative terms. In (76), the king of France is 'de dicto' with respect to one attitude operator (namely, believe) but 'de re' with respect to another (namely, think). The relevant generalization for our cases seems to be that a DP cannot be construed 'de re' and 'de dicto' relative to the same attitude operator. More formally:

(76) A concept generator $G_{n}$ cannot adjoin to any node that dominates a world-pronoun bound by the world-binder of $G_{n}$, or to a trace bound by such a node (where the world-binder of $G_{n}$ is the highest worldbinding lambda c-commanded by $\lambda_{n}$ ).

Interestingly, 'res'-movement avoids some of these issues. Moving the 'res' term up to the attitude verb, as in (77a), places it above the world abstraction operator $\lambda_{1}$. Given the convention that all world pronouns free in the matrix denote the world of evaluation, the truth conditions for (77a) nonsensically require Daley to have a 'de re' belief about the (nonexistent) actual king of France. Iterated cases, on the other hand, work just fine, cf. (77b); the king of France is scoped high enough to be 'de re' in the scope of think, but not so high that it ceases being 'de dicto' in the scope of believe.

(77) a. Daley [believes- $w_{0}$ [the king of France- $w_{1}$ ]]

$$
\left[\lambda_{3} \lambda_{1}\left[t_{3} \text { is a spy- } w_{1}\right]\right]
$$

b. Daley believes- $w_{0}$

$$
\begin{aligned}
& \left.\left[\lambda_{1} \text { [Clinton [thinks- } w_{1} \text { [the king of France- } w_{1}\right]\right] \\
& \left.\left.\left[\lambda_{3} \lambda_{2}\left[t_{3} \text { is a spy- } w_{2}\right]\right]\right]\right]
\end{aligned}
$$

Unsurprisingly, though, given the arguments we developed in this paper, the scoping solution rules out too much - namely 'bound de dicto/de re'

(i) $\llbracket$ Sue thinks- $w_{0}\left[\lambda_{1} \lambda_{i}\right.$ [John believes- $w_{1}\left[\lambda_{8} \lambda_{2} \lambda_{j}\left[\left[\left[G_{8}\right.\right.\right.\right.$ she $\left.\left.e_{i}\right]-w_{2}\right]-x_{j}$ is a bore$\left.\left.\left.\left.w_{2}\right]\right]\right]\right] \rrbracket \rrbracket^{c, g}=1$ iff

$$
\begin{aligned}
\text { DoX }_{\text {Sue }, @} \subseteq\left\{\langle w, x\rangle: \exists G \in \operatorname{CON}(c)_{\text {John }, w, 1}:\right. & \\
& \text { Dox } \left._{\text {John }, w} \subseteq\left\{\left\langle w^{\prime}, x^{\prime}\right\rangle: G(x)\left(w^{\prime}\right)\left(x^{\prime}\right) \text { is a bore in } w^{\prime}\right\}\right\} .
\end{aligned}
$$


Bound 'de re' pronouns and the LFs of attitude reports

constructions. To show this we embed our original 'bound de re' scenario inside an attitude, as it were. Say Sally believes there's three unicorns and that she thinks Bill's in a Quinean double-vision scenario with respect to them - i.e. she thinks Bill believes of Unicorn 1 and its mother that the former likes the latter, and so on, which is to say she thinks Bill's thought is "a likes b's mother,...". Then Sally believes in unicorns, and she believes that Bill thinks every unicorn likes its $_{i}$ mother is true, but it requires an LF that 'res'-movement can't give it: every unicorn needs to stay inside its tensed clause (cf. §2.2.1), but the pronoun it binds needs to go higher to pair up with relational thinks. The concept-generator theory, of course, readily generates a working LF:

(78) $\llbracket$ Sally believes- $w_{0}\left[\lambda_{1}\right.$ Bill thinks- $w_{1}$ $\left[\lambda_{8} \lambda_{9} \lambda_{2}\right.$ [every unicorn- $w_{1}$

$\left[\lambda_{3}\left[\left[G_{8} t_{3}\right]-w_{2}\right.\right.$ likes- $w_{2}\left[G_{9}\right.$ its 3$]-w_{2}$ mother- $\left.\left.\left.\left.\left.w_{2}\right]\right]\right]\right]\right] \rrbracket^{c, g}=1$ iff

$$
\begin{aligned}
& \operatorname{Dox}_{\text {Sally, }} \subseteq\{w: \exists\langle G, H\rangle \in \operatorname{CON}(c)_{\text {Bill }, w, 2}: \\
& \operatorname{Dox}_{\text {Bill }, w} \subseteq\left\{w^{\prime}:\{x: x \text { is a unicorn in } w\} \subseteq\right. \\
&\left.\left.\left\{y: G(y)\left(w^{\prime}\right) \text { likes } \operatorname{MOM}\left(w^{\prime}\right)\left(H(y)\left(w^{\prime}\right)\right)\right\}\right\}\right\} .
\end{aligned}
$$

So while scoping theories of 'de re' ascription (e.g. 'res'-movement) do predict some of the data we've considered in this appendix - this explanation isn't consistent with the full range of 'de dicto/de re' data.

\section{References}

Aloni, Maria. 2001. Quantification under conceptual covers. University of Amsterdam Ph.D. thesis.

Aloni, Maria. 2005. Individual concepts in modal predicate logic. Journal of Philosophical Logic 34(1). 1-64. http://dx.doi.org/10.1007/s10992-0044065-8.

Anand, Pranav. 2006. De de se. Cambridge, MA: MIT Ph.D. thesis.

Anand, Pranav. 2007. Dream report pronouns, local binding, and attitudes de se. Semantics and Linguistics Theory (SALT) 17. 1-18.

Chierchia, Gennaro. 2001. A puzzle about indefinites. In Carlo Cecchetto, Gennaro Chierchia \& Maria Teresa Guasti (eds.), Semantic interfaces: Reference, anaphora, and aspect. Stanford: CSLI. 
Cresswell, Maxwell J. \& Arnim von Stechow. 1982. De re belief generalized. Linguistics and Philosophy 5(4). 503-535. http://dx.doi.org/10.1007/ BFoO355585.

Elbourne, Paul. 2005. Situations and individuals. Cambridge, MA: MIT Press.

Fillmore, Charles. 1963. The position of embedding transformations in grammar. Word 19. 208-231.

Fodor, Janet Dean. 1970. The linguistic description of opaque contexts. Cambridge, MA: MIT Ph.D. thesis.

Heim, Irene. 1992. Presupposition projection and the semantics of attitude verbs. Journal of Semantics 9(3). 183-221. http://dx.doi.org/10.1093/jos/ 9.3.183.

Heim, Irene. 1994. Comments on Abusch's theory of tense. In Hans Kamp (ed.), Ellipsis, tense and questions, DYANA deliverable R2.2.B, 143-170. Amsterdam: University of Amsterdam.

Heim, Irene \& Angelika Kratzer. 1998. Semantics in generative grammar. Oxford: Blackwell.

Hintikka, Jaakko. 1962. Knowledge and belief: An introduction to the logic of two notions. New York: Cornell University Press.

Hintikka, Jaakko. 1969. Semantics for propositional attitudes. In John Whitney Davis, Donald James Hockney \& Warren Kent Wilson (eds.), Philosophical logic, 21-45. Dordrecht: Reidel.

Horn, Laurence. 1978. Remarks on neg-raising. In Peter Cole (ed.), Pragmatics (Syntax and Semantics 9), 129-220. New York: Academic Press.

Jacobson, Pauline. 1999. Towards a variable-free semantics. Linguistics and Philosophy 22. 117-184. http://dx.doi.org/10.1023/A:1005464228727.

Kaplan, David. 1968. Quantifying in. Synthese 19(1). 178-214. http://dx.doi. org/10.1007/BFoo568057.

Kratzer, Angelika. 1998. Scope or pseudoscope? Are there wide scope indefinites? In Susan Rothstein (ed.), Events and grammar, 163-196. Dordrecht: Kluwer.

Kratzer, Angelika. 2003. Choice functions in context. Unpublished ms., University of Massachusetts, Amherst.

Lewis, David. 1979. Attitudes de dicto and de se. The Philosophical Review 88. 513-543. http://dx.doi.org/10.2307/2184843.

Percus, Orin. 2000. Constraints on some other variables in syntax. Natural Language Semantics 8 (3). 173-229. http://dx.doi.org/10.1023/A: 1011298526791. 
Bound 'de re' pronouns and the LFs of attitude reports

Percus, Orin. 2010. The syntax of de re. Talk presented at the A Matter of Attitude Workshop, Goettingen, December 2010.

Percus, Orin \& Uli Sauerland. 2003. On the LFs of attitude reports. Sinn und Bedeutung 7. 228-242.

Quine, W. V. 1956. Quantifiers and propositional attitudes. The Journal of Philosophy 53(5). 177-187.

Reinhart, Tanya. 1997. Quantifier scope: How labor is divided between QR and choice functions. Linguistics and Philosophy 20(4). 335-397. http: //dx.doi.org/10.1023/A:1005349801431.

Ross, John. 1967. Constraints on variables in syntax. Cambridge, MA: MIT PhD thesis.

Russell, Bertrand. 1905. On denoting. Mind XIV(4). 479-493. http://dx.doi. org/10.1093/mind/XIV.4.479.

Schlenker, Philippe. 2006. Scopal independence: A note on branching and wide scope readings of indefinites and disjunctions. Journal of Semantics 23(3). 281-314. http://dx.doi.org/10.1093/jos/ffloo5.

Schwager, Magdalena. 2010. Speaking of qualities. Semantics and Linguistic Theory (SALT) 19. 395-412.

Schwarzschild, Roger. 1996. Pluralities. Dordrecht: Kluwer Academic Publishers.

Schwarzschild, Roger. 2002. Singleton indefinites. Journal of Semantics 19(3). 289-314. http://dx.doi.org/10.1093/jos/19.3.289.

Sharvit, Yael. 2011. Covaluation and unexpected BT effects. Journal of Semantics 28(1). 55-106. http://dx.doi.org/10.1093/jos/ffqo12.

Solomon, Michael. 2011. True distributivity and the functional interpretation of indefinites. Unpublished ms., New York University.

Simon Charlow

Department of Linguistics

New York University

New York, NY 10003

simon.charlow@nyu.edu
Yael Sharvit

Department of Linguistics

University of California, Los Angeles

Los Angeles, CA 90095

ysharvit@gmail.com 